\title{
1995107811
}

\section{PROTEIN CRYSTAL GROWTH RESULTS FROM THE UNITED STATES MICROGRAVITY LABORATORY - 1 MISSION}

"DeLucas, L. J., Moore, K. M., van der Woerd, M., Bray, T. L., Smith, C., Carson, M., Narayana, S. V. L., Rosenblum, W. M., Carter, D., Clark, Jr., A. D., Nanni, R. G., Ding, J., Jacobo-Molina, A., Kamer, G., Hughes, S. H., Arnold, E., Einspahr, H. M., Clancy, L. L., Rao, G. S. J., Cook, P. F., Harris, B. G., Munson, S. H., Finzel, B. C., McPherson, A., Weber, P. C., Lewandowski, F. A., Navia, M. A., Wilson, K. P., Thomson, J. A., Meade, C. J., Bishop, S. P., Dunbar, B. J., Trinh, E., Prahl, J., Sacco, Jr., A., and Bugg, C. E.

\author{
* Deputy Director \\ Center for Macromolecular Crystallography \\ University of Alabama at Birmingham \\ Birmingham, Alabama
}

\begin{abstract}
Protein crystal growth experiments have been performed by this laboratory on 18 space shuttle
\end{abstract} missions since April, 1985. In addition, a number of microgravity experiments have also been performed and reported by other investigators, $(1-7)$. These space shuttle missions have been used to grow crystals of a variety of proteins using vapor diffusion, liquid diffusion, and temperature-induced crystallization techniques. The Unifed States Microgravity Laboratory - 1 mission (USML-1, June 25 July 9, 1992) was a Spacelab mission dedicated to experiments involved in materials processing. New protein crystal growth hardware was developed to allow in orbit examination of initial crystal growth results, the knowledge from which was used on subsequent days to prepare new crystal growth experiments. In addition, new seeding hardware and techniques were tested as well as techniques that would prepare crystals for analysis by x-ray diffraction, a capability projected for the planned Space Station. Hardware that was specifically developed for the USML-1 mission will be discussed along with the experimental results from this mission.

\section{INTRODUCTION}

The study of protein crystal growth in microgravity has generated considerable interest in recent years. Through the support of the National Aeronautics and Space Administration (NASA), we have coordinated a program designed to study protein crystal growth processes in general, and have evaluated the affects of a microgravity environment on these processes. A large co-investigator group, consisting of researchers and/or engineers from universities, NASA, and aerospace or pharmaceutical companies, participated in the hardware development and scientific experiments. Since April, 1985,

Joint "L+1" Science Review for USML-1 and USMP-1 with the Microgravity Measurement Group, September 22-24, 1993, Huntsille, Alabama, USA. 
experiments have been performed on eighteen $U$. S. Space Shuttle missions with a variety of crystal growth hardware and crystallization techniques. In a number of cases, results from these experiments indicate that proteins grown in microgravity may be larger, display more uniform morphologies, and yield diffraction data to significantly higher resolutions than the best crystals of these proteins grown on Earth.(8 - 11) This paper will discuss the hardware specifically developed for the USML-1 mission and the results obtained for the proteins flown on this mission.

\section{HARDWARE DEVELOPMENT}

\section{A. Vapor Diffusion Apparatus}

A vapor diffusion apparatus (VDA) $(9,12,13)$ was used for protein crystallization experiments on thirteen different space shuttle missions. This hardware incorporates a vapor diffusion technique that is closely related to the widely used hanging drop method of protein crystal growth on Earth. (14) This method was chosen for several reasons: 1 . most protein crystallography laboratories have extensive experience with this method and a large percentage of the protein crystals described in recent publications have been obtained by this technique; 2 . this technique is particularly amenable to crystallization experiments involving small quantities of protein; 3 . in a microgravity environment, relatively large, stable droplets of protein solution can be formed with minimal surface contacts, thereby decreasing possible nucleation sites and minimizing wall effects that generally accompany crystallization experiments on Earth. The hardware was developed from a simple piece of equipment that was easily modified and improved throughout the series of shuttle missions. $(9,12,13)$

Although microgravity experiments with the VDA clearly demonstrate the beneficial effects of this environment for protein crystal growth, only about $20 \%$ of the proteins examined were found to exhibit better morphologies or better quality data than their Earth-grown counterparts. Approximately $40 \%$ of the space experiments failed to produce crystals, and the remaining $40 \%$ yielded crystals that were either too small for $x$-ray analysis or produced data no better than that obtained from the best Earth-grown crystals. It is important to note that results from a single space experiment, in which each protein is typically allotted five crystallization chambers, are being compared to the best crystals ever produced for that particular protein by any method on Earth. Investigators have no opportunity to optimize crystal growth conditions in microgravity. This may account for some occasions in which unsatisfactory results were obtained in microgravity.

\section{B. USML-1 Glovebox Vapor Diffusion Hardware:}

To allow crewmen to optimize microgravity crystal growth conditions, new hardware was developed and flown on the USML-1 mission in June, 1992. A glovebox was available in the Spacelab 
module for this mission, providing sufficient containment that liquids (i. e. proteins, buffers, etc.) could be manipulated by methods similar to those employed on Earth. The hardware developed for this mission incorporated several new capabilities: 1. optimization of crystal growth experiments; 2 . in-orbit seeding with small crystals produced in microgravity; 3 . investigation of crystal-mounting techniques for future shuttle missions and for the planned Space Station; 4. use of video transmission of experimental results to facilitate scientific input from the ground regarding new experiments to be prepared in orbit.

Figure 1 shows the design of the vapor diffusion apparatus. Each chamber (constructed from clear polysulfone material) consists of a rectangular upper and lower half sealed by a neoprene gasket. The upper half contains the protein solutions to be used for three separate vapor diffusion experiments while the opposing half contains depressions which hold their respective reservoir solutions.

The protein and reservoir solutions are prepared on the shuttle using Hamilton syringes in conjunction with a dispensing device that allows microliter quantities to be extruded accurately and rapidly (figure 2). The solutions used to prepare these experiments are contained in vials/bottles with rubber septa so that they can be accessed via the Hamilton syringes (figure 2). Solutions are dispensed into the polysulfone chambers and mixed by withdrawing and re-extruding them from the syringes and/or by gentle stirring with the end of the syringe needle.

After all three crystallization experiments have been prepared, the crystallization chambers are placed together and sealed by tightening a thumbscrew. The experiments can be deactivated (the vapor diffusion process terminated) by a $180^{\circ}$ rotation of the upper half of the experimental chamber. Eight chambers (24 vapor-diffusion experiments) are stored in a holder which fits into a lexan containment tube, thereby providing a second level of containment for the fluids. Thirty two of these containment tubes (768 experiments) can be placed into a tray which slides into the refrigerator/incubator module (R/IM) so that a precise temperature can be maintained throughout the crystallization process (figure 3 ).

In addition, a commercial micro-manipulator ( $x-y-z$ translation stage) was adapted to hold a . manostat syringe on which capillaries could be attached for crystal mounting (figure 4). The translation stage is attached to a magnetic base that can be affixed to the metal floor of the USML-1 glovebox. Each vapor diffusion experiment could be observed by placing the experiment chamber in a speclally constructed $x-y-z$ translation stage with fiber optic back lighting (figure 4). This stage was subsequently used to prepare and observe experiments via a Zeiss binocular microscope with a special adapter that allowed $35 \mathrm{~mm}$ photography and/or real time video transmission of the crystals to scientists on Earth.

\section{Experimental}

The VDA performed flawlessly on this mission. However, it was clear from the photographic sessions taken on day 6 that very little mixing had occurred for the more viscous solutions (i. e. high 
molecular weight polyethylene glycols) used to crystallize various proteins. A sharp demarcation (due to a refractive index change) could be seen between the protein and precipitating agent solution indicating that very little mixing had occurred. It was clear from this observation that a new enhanced mixing syringe is necessary for the more viscous solutions used in these experiments.

There were 2 major problems encountered when the glovebox hardware was tested. Commercial Hamilton syringes were used to withdraw liquid (protein, buffer or precipitating agent) for preparation of the experiment in the vapor diffusion chambers. Unfortunately, several of the crystallization solutions produced hundreds of small bubbles when withdrawn into the syringe. The bubbles had to be eliminated by manual centrifugation of the syringe by the crewman, since they would affect accuracy while dispensing solutions. This procedure caused the bubbles to coalesce on one end of the syringe thereby allowing the solution to be precisely dispensed for these experiments. A second problem encountered was difficulty in positioning the protein droplet in the center of the experimental chamber. Once the droplet was extruded from the syringe, it was stirred to ensure adequate mixing of solutions. The stirring action caused droplets to slide along the polysulfone material, often merging with the chamber walls, and spreading into a thin layer, which adversely affected the vapor equilibration profile. Even when droplets were properly positioned, on subsequent days it was noticed that several droplets had repositioned themselves along the chamber wall, which again adversely affected the vapor diffusion profile for these delicate experiments. These two problems are currently being addressed by: 1. the design of a new improved syringe that should minimize bubble formation; 2 . the design of new experimental vapor diffusion chambers with multiple pinning edges to contain droplets of varying sizes.

After the mission, the experimental chambers were returned to UAB so that the crystals could be analyzed. Laboratory co-investigators found it very difficult to retrieve some of the crystals, as droplets had moved to the corners of the crystallization chamber in almost every case. It is believed that this was due to the orientation of the hardware during the re-entry high-g profile. As a result, the new experimental chambers are being designed so that their orientation will minimize the adverse effects of higher g-loads experienced by the shuttle on re-entry.

\section{X-Ray Analysis}

Because evaluation of diffraction resolutions from photographs is highly subjective, and is often dependent on crystal orientations, we have depended primarily on three-dimensional intensity data sets for comparison of space- and Earth-grown crystals.

Intensity data sets from crystals were analyzed in a variety of different ways. The largest Bragg angles at which usable data could be measured were assembled, and the percentage of data above background levels through the data collection range was evaluated. Plots were made of average I/ $\sigma$ (I) 
values, where $I$ is intensity, versus diffraction resolution and of percentages of data above various cutoff levels as functions of resolution. Data sets from space- and Earth-grown crystals were compared by using Wilson plots (15). The Wilson plot can be used to estimate the overall B values for a crystal, the B value being a parameter that reflects the internal order within a crystal. Relative Wiison plots, also known as difference Wilson plots (15), are useful for assessing changes in the internal order of protein crystals. These plots of $\ln \left(\Sigma \mathrm{Fa}^{2} / \Sigma \mathrm{Fb}^{2}\right)$, where $F$ is the crystallographic structure factor for crystals of type $a$ and $b$, versus $4 \sin ^{2} \theta / \lambda^{2}$ (resolution) are routinely used to characterize and compensate for the disordering effects resulting from the diffusion of heavy-atom derivatives into protein crystals. The slopes of these plots are directly related to the difference in overall B values for two different crystals, a (space-grown) and b (Earth-grown).

\section{RESULTS AND DISCUSSION}

A total of 33 proteins (table 1) were selected for crystallization experiments on USML-1. It should be noted that for all previous protein crystal growth experiments performed on Space Shuttle missions, proteins are chosen by a selection committee. This committee typically chooses $30 \%$ of those proteins submitted by co-investigators involved in this project. The proteins that are not selected generally fall into one of two main categories: 1 . crystallization time is too long for that particular shuttle flight; 2 . the protein is very flexible, not stable, not pure, or insufficient ground-based data is available. For the USML-1 mission, it was clear that several proteins selected to fly would fall into one of these two categories. On any other shuttle mission, these proteins would not have been accepted by the committee, but since this mission was unprecedented in that a protein crystallographer would actually accompany and be able to perform these experiments on the shuttle, it was decided that every protein submitted would be flown if possible. Since several of the proteins clearly needed growth periods longer than would be available on this 13 day mission, those proteins were given a lower priority which resulted in typically only one or two vapor diffusion experiments being set up. The experiments were performed on 9 proteins in a $4^{\circ} \mathrm{C}$ incubator and 10 proteins in a $22^{\circ} \mathrm{C}$ incubator using the VDA flown on several previous missions. Activation occurred on the first day of the mission and deactivation one day prior to re-entry, thereby allowing thirteen days for crystal growth in microgravity. In addition, 24 proteins (some of which were the same as those in the VDA's housed in the $22^{\circ} \mathrm{C}$ incubator) were crystallized throughout the mission using the glovebox hardware described in the previous section. Once these experiments were prepared, they were transported back to the middeck and housed in a third incubator set at $22^{\circ} \mathrm{C}$. On subsequent days, the glovebox crystallization experiments were observed using a binocular zoom microscope ( $8 x$ to $64 x$ magnification). Fourteen of the twenty-four proteins prepared in the glovebox required between seven and fourteen days to crystallize in experiments previously 
prepared on Earth. As expected, these proteins took at least as long and typically longer to crystallize in microgravity and, as a result, by day thirteen, most of these proteins had recently nucleated and, therefore, failed to grow to an adequate size for diffraction experiments. However, of the remaining ten proteins crystallized in the glovebox, several produced high quality diffraction size crystals, some of which were the largest crystals ever grown. Proteins grown in the glovebox that produced diffraction size crystals included canavalin, malic enzyme, reverse transcriptase, lysozyme, horse serum albumin, factor $D$, mouse monoclonal antibody, and human $\alpha$-thrombin.

Four proteins that were crystallized with the glovebox hardware had flown on one or more previous shuttle missions using the VDA hardware. VDA results for these proteins did not produce crystals; this may be due to inadequate mixing of the protein and viscous polyethylene glycol precipitant solutions. With the glovebox hardware, the experimenter could mix the protein and precipitant solutions thoroughly by stirring or by withdrawing and re-extruding the solution from a Hamilton syringe. As a result, all four proteins produced crystals, and crystals of two of the proteins, malic enzyme and factor $D$, produced high quality $x$-ray diffraction data.

Malic enzyme, (M.W. $=260$ kilodaltons) is an NAD-dependent enzyme isolated from a parasitic nematode. It is being studied to exploit structural differences from the human form of this enzyme to aid in the development of an antiparasitic drug. Malic enzyme was flown on two previous shuttle missions using the VDA with no crystals found at the conclusion of the flights. This lack of success was attributed to inadequate mixing of the viscous precipitating agent (polyethylene glycol 4000). On the USML-1 mission with the glovebox crystallization hardware, the viscous solutions were mixed by excessive stirring of the solutions using the syringe needle tip and, as a result, many small crystals were observed within 5 days. Based on observations made through a binocular microscope in orbit, new conditions were chosen (i.e. lower polyethylene glycol concentrations) that ultimately produced the best crystals (figure 5). Earth-grown crystals of malic enzyme diffract weakly to $3.2 \AA$ resolution. With crystals obtained in microgravity, the ultimate resolution limit achieved was $2.6 \AA$.

Figure 6a shows the comparison of diffraction intensity data for a space-grown crystal and some of the best Earth-grown crystals. It should be noted that the Earth-grown crystal was 5 times the volume of the space-grown crystal used for this comparison. Nonetheless, the space-grown crystal of malic enzyme produced data with increased signal to noise ratio at all resolution ranges, with an appreciable enhancement in the highest resolution range at which measurable data were obtained. The space-grown crystal, although only $1 / 5$ the volume of the Earth-grown crystal, yielded $\approx 25 \%$ more data. Figure $6 \mathrm{~b}$ shows a comparison of the data collected from similar resolution bins for the Earth and space crystals. In addition, a relative Wilson plot comparing the space-grown crystal to the best Earth-grown crystal revealed better internal order for the space-grown crystal (figure 6c). 
Based on glovebox results obtained for malic enzyme and other proteins that used viscous precipitating agents, it was clear that the VDA results for these proteins were adversely affected due to the lack of adequate mixing of the protein and precipitating solutions. As a result, a syringe that provided enhanced mixing was designed and flown on a subsequent flight (Spacehab 1, STS-57) with dramatic results. For this experiment, 10 of the original syringes were loaded with malic enzyme and its precipitating agent at varying concentrations and an additional 10 new syringes were loaded with identical conditions. After the 9 day Space Shuttle flight, the original syringes contained only clear solution while 8 of the 10 syringes designed to provide enhanced mixing yielded small well-formed crystals of malic enzyme. These crystals were subjected to a detailed $x$-ray analysis and compared with control crystals grown with the same batch of protein. The space crystals typically measured $0.17 \mathrm{~mm}^{3}$ while the Earth-grown control crystals measured $0.5 \mathrm{~mm}^{3}$. In spite of the significant increase in volume for the Earth control crystals, the space-grown crystals produced significantly better data. (figure 7 ) in addition, an analysis of the decay due to $x$-ray radiation for several of the space and Earth crystals was conducted. (figure 8) The space-grown crystals displayed much longer lifetimes when subjected to radiation than did their Earth-grown counterparts. Although other investigators have noted similar results for other proteins, this represents the first detailed analysis indicating the enhanced stability of spacegrown crystals.

Bovine brain prolyl-isomerase, (M. W. $=12$ kilodaltons) is the target for a new class of drugs designed to prevent transplant rejection. When crystallized on Earth, this enzyme often forms clusters that twin and are of variable diffraction quality. The crystallization solutions used for this shuttle mission were identical to those used on Earth, yet the space-grown crystals (figure 9) were substantially larger (approaching $3.0 \mathrm{~mm} \times 1.0 \mathrm{~mm}$ thick as opposed to $0.6 \mathrm{~mm} \times 0.2 \mathrm{~mm}$ for Earth-grown crystals) and exhibit no clustering, twinning, or large variations in diffraction quality.

The space-grown crystals were even large enough that one might consider neutron-diffraction experiments. The space-grown crystals also had sharper edges and were clearer than their Earth-grown counterparts. Unfortunately, the space-grown crystals suffered some degradation (founding of edges and facets) before they could be examined at the co-investigators $x$-ray laboratory. (The cause of this degradation is not known). This degradation may have affected the diffraction quality of the space-grown crystals. In spite of this, a complete data set to $2.3 \AA$ resolution was collected on the best crystal. When these data are compared to those from the best Earth-grown crystals, one can see that diffraction from the space-grown crystal is superior to $2.5 \AA$ resolution (figure 10).

Factor $D(M . W .=24$ kilodaltons) is an essential enzyme for the initiation of the alternative pathway of the complement system. Two crystalline forms, triclinic (space group P1) and monoclinic (space group $\mathrm{P} 21$ ) can be produced using identical crystallization conditions. The monoclinic form was 
used to determine the three-dimensional structure. However, these crystals are extremely difficult to grow on a reproducible basis. In fact, using several different batches of protein over a ten month period (including the batch used for the USML-1 microgravity experiments), it was not possible to produce monoclinic crystals. On USML-1, one monoclinic crystal was produced using the glovebox hardware. This crystal was the longest crystal ever grown of factor $D$ (although it was only $1 / 3$ as thick as the best Earth-grown crystal) and produced diffraction data comparable in intensity to the best Earth-grown crystal, but with a slight improvement in resolution $(0.1 \AA)$. The relative Wilson plot revealed a significant difference in $\mathrm{B}$ values for data in the higher resolution range, indicating better internal order for the space-grown crystal. Using the monoclinic space crystals combined with previously grown Earth crystals, the three-dimensional structure of factor $D$ (figure 11) was recently determined and is in press with the Journal of Molecular Biology. This represents the first structure of a complement protein ever determined at atomic resolution.

Canavalin (M. W. = 11 kilodaltons) is the major storage protein of leguminous plants and an important source of dietary protein for humans and domestic animals. This protein has been crystallized on several shuttle flights using the VDA hardware. For USML-1, large crystals of recombinant canavalin were grown both in the VDA and glovebox hardware. However, canavalin crystals are extremely unstable and as a result, several exhibited severe degradation by the time the crystals were harvested after the shuttle flight. One VDA experiment produced crystals that, although somewhat degraded, were suitable for $x$-ray data collection. From this experiment, three large nombohedral crystals were obtained for data collection on an SDMS area detector system. Comparison of average I / $\sigma$ (I) versus resolution for the two space crystals with the best Earth-grown crystals demonstrated a marginal improvement for those crystals grown in space. However, Relative Wilson statistics were not conclusive, indicating that the data produced from microgravity-grown crystals were quite similar to those produced by equivalent crystals grown in the laboratory. Although the average I/ $\sigma$ (I) ratio was not improved, an extension of the resolution to higher limits was observed for the space-grown crystal near the high resolution data range (figure 12). This indicates that if the crystal had not experienced the significant decay, it is likely that it would have produced superior data to that of its Earth-grown counterparts. On previous missions, native space-grown canavalin crystals showed more dramatic improvements in diffraction quality (figure 13).

Human $\alpha$-thrombin (M. W. $=36.5$ kilodaltons) is a serine protease involved in the final step of the coagulation cascade cleaving soluble fibrinogen to produce insoluble fibrin. For the USML-1 mission, experiments on $\alpha$-thrombin yielded several large single crystals and some clusters of smaller crystals. One a-thrombin crystal grown on this space shuttle flight measured $1.0 \mathrm{~mm} \times 0.5 \mathrm{~mm} \times 0.45 \mathrm{~mm}$ which is a larger size than typically observed in the lab. The crystal was rectangular in shape with a hollow 
area along one edge indicating possible rapid and incomplete crystal growth. The other crystals were perfect in habit, a phenomenon rarely observed for crystals grown on Earth.

Large crystals of HIV-1 reverse transcriptase complexed to a monoclonal antibody Fab fragment and to a $19 / 18$ base-paired double stranded DNA helical fragment ( $M . W .=180$ kilodaltons) were grown in the $4^{\circ} \mathrm{C} R / I M$. Reverse Transcriptase is an enzyme responsible for copying the nucleic acid genome of the AIDS virus from RNA to DNA. Both space-grown and Earth-grown crystals were examined by $x$ ray oscillation photography at the F1 station of the Cornell High Energy Synchrotron Source (CHESS) with an $x$-ray wavelength of $0.91 \AA$. Exposure times for both the space crystals and the Earth-grown crystals were 6 to 8 seconds with an oscillation range of $0.7^{\circ}$. Fuji storage-phosphor imaging plates were the $x$-ray detection medium with a crystal-to-detector distance of $340 \mathrm{~mm}$. The crystals were large enough (typically $0.8 \mathrm{~mm}$ ) to permit translation within the beam so that photographs could be taken from multiple positions of the crystals. A total of 101 exposures from 23 space-grown crystals were obtained, from which 88 exposures from 22 crystals proved satisfactory and therefore were included in the final space-crystal data set. For the ground control crystals, 27 exposures were collected from 5 crystals, with 22 of these exposures included in the final control data set. Plots of intensities greater than various $s$ cutoffs versus resolution as well as average $I / \sigma(I)$ versus resolution indicate that there is very little difference between the space and ground crystals. However, a relative Wilson plot indicated that the space-grown crystals had a significantly lower $B$ value than the ground control crystals, particularly at the high resolution end of the plot (figure 14).

This is an indication that the space-grown crystals are better ordered (beyond $4 \AA$ ) than are the Earth-grown crystals. Differences in the post-refined unit cell parameters were less than one-half of one percent. The post-refined vertical and horizontal mosaic spread parameters were similar $\left(0.23^{\circ}\right.$ to $\left.0.29^{\circ}\right)$ for all crystals.

Other proteins that produced diffraction-sized crystals showed diffraction data either equal in quality or of poorer quality than the best crystals of these proteins produced on Earth. In all of these cases, the crystals grown in space were significantly smaller than the Earth-grown crystals.

\section{CONCLUSION}

The USML-1 glovebox hardware was extremely successful in that it demonstrated the usefulness of altering crystallization conditions based on previous results in an attempt to improve the quality of crystals that are grown in space. By comparing results from the glovebox with those for the same protein in the VDA, it was realized that the success rate of these experiments had been adversely affected due to the viscous nature of the crystallizing solutions. The VDA apparatus did not adequately mix these solutions and, therefore, either a clear solution or precipitated protein resulted at the end of the 
microgravity experiment. By carefully mixing the solutions using the glovebox hardware, high quality crystals of four proteins were produced that had not yielded successful results using the VDA apparatus.

A micro-manipulator was used to withdraw small seed crystals grown on previous days with the glovebox hardware. This procedure proved to be straightforward and quite useful, although the seed crystals that were injected into new growth solutions never reached a large enough size to be useful for diffraction experiments. In several cases, however, investigators commented that the crystals obtained were of extremely high quality, although small. As a result, these crystals were used as seed crystals for Earth-based crystallization experiments performed after the mission. It was clear during the seeding operation that mounting protein crystals in x-ray capillaries in microgravity is actually easier to successfully complete than it is on Earth. Since the crystals are typically suspended within the middle of the protein drop, the most difficult aspect of this procedure (withdrawing the crystal into the capillary) was easily accomplished in microgravity. The end of the capillary was positioned directly over the crystal, and subsequently withdrawn into the capillary.

It was clear that high magnification microscopy with video transmission will be extremely useful on future missions. This capability will allow crewmen to display results to scientists stationed on the ground so that they can aid in the decision making process thereby optimizing the chance of producing high quality crystals.

In conjunction with co-investigators from universities and pharmaceutical companies and with scientists and engineers from the Marshall Space Flight Center, this laboratory has conducted protein crystal growth experiments utilizing vapor diffusion and/or temperature-induced crystallization on 18 different space shuttle missions. These initial experiments have demonstrated that the microgravity environment present on the space shuttle is beneficial for protein crystal growth experiments. From these few space experiments there are several examples where crystals were grown that were larger, displayed more uniform morphologies, and/or yielded diffraction data to significantly higher resolutions than the best crystals of these proteins grown on Earth by any method. Table 2 summarizes the positive results obtained from these space shuttle missions. Resolution enhancements have ranged from $0.1 \AA$ to as much as $2.0 \AA$ for the space-grown crystals. It should be noted that in several cases where significant resolution enhancements occurred, the space-grown crystals were much smaller in volume than the Earth crystals with which they were being compared. This strongly indicates that the spacegrown crystals are more highly ordered at the atomic level. However, in those cases where space-grown crystals were larger, increases in size as much as an order of magnitude were observed which, in some cases, resulted in $x$-ray diffraction resolution enhancements in excess of $0.5 \AA$. The success rate in the VDA is approximately $20 \%$, which is quite remarkable since each protein included in the space experiments is crystallized with only a few experiments, usually about 5 experimental chambers are 
allotted to each investigator per flight. These space results are then compared with the best crystals ever produced on the ground using any crystallization method (usually hundreds of crystallization conditions were tested on the ground to optimize the crystal growth conditions).

Temperature-induced crystallization (16 - 20) is often the method of choice when large quantities of protein are available and large batches of crystals are required. It is particularly suited for a microgravity environment because temperature-induced convective flow is minimized, thereby providing a more quiescent environment for both the nucleation and subsequent crystal growth stages. This method provides the experimenter with the ability to influence the number, size and quality of protein crystals by precisely controlling the rate of temperature change and, therefore, the protein saturation levels throughout the experiment. Temperature-induced crystallization was performed on 4 separate shuttle flights with high success. Crystals from all 4 shuttle flights were significantly (2 times to as much as 10 times) larger than the best of their Earth-grown counterparts. In addition, $x$-ray diffraction data for the space-grown crystals showed significant improvements.

These initial experiments have been instrumental in allowing our co-investigator group to better understand the possible benefits of the microgravity environment. Results from the VDA have led to the development of a second generation of hardware to perform vapor diffusion experiments. This hardware provides a number of advantages over the existing hardware including: 1 . thorough mixing of the protein and precipitant samples in orbit; 2 . real time video monitoring capabilities; and, 3. precise control over equilibration rates. The new enhanced mixing syringe flown on STS-57 conclusively demonstrated that viscous solutions can be completely mixed in microgravity, thereby improving the success rate for these experiments. The combination of dynamic control combined with sensitive optical analysis capabilities will enhance our understanding of the basic mechanisms involved in macromolecular crystal growth processes as well as increasing the overall success of these experiments. We anticipate completing the fabrication of the flight unit by 1996. During this three year period, extensive testing of a laboratory "breadboard" unit will be conducted. This system should improve crystallization results on Earth and provide valuable information regarding the basic mechanisms involved in protein crystal growth processes. 


\section{REFERENCES}

1. Hilgenfeld, R., Liesum, A., Storm, R., and Plaas-Link, A., "Crystallization of Two Bacterial Enzymes on an Unmanned Space Mission", Journal of Crystal Growth, 122: 330 - 336 (1992)

2. Snyder, R. S., Fuhrmann, K., and Walter, H. U., "Protein Crystallization Facilities for Microgravity Experiments", Journal of Cystal Growth, 110: 333 - 338 (1991)

3. Asano, K., Fujita, S., Senda, T., and Mitsui, Y., "Crystal Growth of Ribonuclease S Under Microgravity", Joumal of Crystal Growth, 122: 323 - 329 (1992)

4. Littke, W. and John, C., "Protein Single Crystal Growth Under Microgravity", Science, 225: 203 205 (1984)

5. Day, J., and McPherson, A., "Macromolecular Crystal Growth Experiments on International Microgravity Laboratory - $1^{n}$, Protein Science, I: $1254-1268$ (1992)

6. McPherson, A., Greenwood, A., and Day, J. "The Effect of Microgravity on Protein Crystal Growth, Advances in Space Research 11: 343 - 356 (1991)

7. Erdmann, V. A., Lippmann, C., Betzel, C., Dauter, Z., Wilson, K., Hilgenfeld, R., Hoven, J., Liesum, A., Saenger, W., Muller-Fahrnow, A., Hinrichs, W., Duvel, M., Schulz, G., Muller, C. W., Wittmann, H. G., Yonath, A., Weber, G., Stegen, K., and Plaas-Link, A., "Crystallization of Protein Under Microgravity", FEBS Letters, 259: 194 - 198 (1989)

8. DeLucas, L.J., Smith, C. D., Smith, W. H., Kumar, S. V., Senadhi, S. E., Ealick, S.E., Carter, D. C., Snyder, R. S., Weber, P. C., Salemme, R., Ohlendorf, D. H., Navia, M. A., McKeefer, B. M., Nagabhushan, T. L., Nelson, G. and Bugg, C. E., "Protein Crystal Growth in Microgravity", Science, 246: $651-654$ (1989)

9. DeLucas, L. J., Smith, C. D., Ealick, S. E., Carter, D. C., Twigg, P., He, X.-M., Snyder, R. S., Weber, P. C., Schloss, J. V., Einspahr, H. M., Clancy, L. L., McPherson, A., Koszelak, S., Vandonselaar, M. M., Prasad, L., Quail, J. W., Delbaere, L. T. J., and Bugg, C. E., Proceedings of the Committee on Space Research (COSPAR) XXVIII Plenary Meeting, The Hague, The Netherlands, "Protein Crystal Growth Aboard the U. S. Space Shuttle Flights STS-31 and STS-32", Advances in Space Research, Vol. 12, No. 1: 393 - 400 (1992)

10. DeLucas, L. J., Moore, K. M., Narayana, S. V. L., Bray, T. L., Rosenblum, W. M., Einspahr, H. M., Clancy, L. L., Rao, G. S. J., Harris, B. G., Munson, S. H., Finzel, B. C., and Bugg, C. E., "Protein Crystal Growth Results from the United States Microgravity Laboratory - 1 Mission", Journal of Physics D: Applied Physics 26: B100 - B103 (1993)

11. DeLucas, L. J., Long, M. M., Moore, K. M., Smith, C., Carson, M., Narayana, S. V. L., Carter, D., Clark, Jr., A. D., Nanni, R. G., Ding, J., Jacobo-Molina, A., Kamer, G., Hughes, S. H., Arnold, E., Einspahr, H. M. Clancy, L. L., Rao, G. S. J., Cook, P. F., Harris, B. G., Munson, S. H., Finzel, B. C., McPherson, A., Weber, P. C., Lewandowski, F., Nagabhushan, T. L., Trotta, P. P., Reichert, P., Navia, M. A., Wilson, K. P., Thompson, J. A., Meade, C., Bishop, S. P., Dunbar, B. J., Trinh, E., Prahl, J., Sacco, Jr., A., and Bugg, C. E. "Recent Results and New Hardware Developments for Protein Crystal Growth in Microgravity". Journal of Crystal Growth, submitted (1993) 
12. DeLucas, L. J., Suddath, F. L., Snyder R., Naumann, R., Broom, M. B., Pusey, M., Yost, V., Herren, B., Carter, D., Nelson, B., Meehan, E. J., McPherson, A., and Bugg, C. E. "Preliminary Investigations of Protein Crystal Growth Using the Space Shuttle", Joumal of Crystal Growth 76: $681-693$ (1986)

13. DeLucas, L. J., and Bugg, C. E., "Protein Crystal Growth Procedure for the U. S. Space Shuttle", METHODS: A Companion to Methods in Enzymology, Vol. 1, \#1: 105 - 109 (1990)

14. McPherson, A., Methods in Enzymology, vol. 114, pp 112 - 119, Diffraction Methods, eds., Hirs, C.H.W., Timasheff, S. N., and Wyckoff, H. W., Academic Press, Orlando, Florida (1985)

15. Blundell, T.L., and Johnson, L.J., Protein Crystallography, pp 333 - 336, Academic Press, New York (1976)

16. Baker, E. N. and Dodson, G., "X-ray Diffraction Data on Some Crystalline Varieties of Insulin", Journal of Molecular Biology 54: 605 - 609 (1970)

17. Longley, W., "Crystalline Structure of Bovine Liver Catalase: A Combined Study by X-ray Diffraction and Electron Microscopy", Journal of Molecular Biology, 30: 323 - 329 (1967)

18. Jakoby, W. B., "A Technique for the Crystallization of Proteins", Analytical Biochemistry, 26: 295 298 (1968)

19. Jakoby, W. B., "Crystallization as a Purification Technique", Methods in Enzymology, 11: 248 - 252 (1971)

20. Hanson, A. W., "X-ray Studies on Single Crystals of Escherichia Coli Alkaline Phosphatase", Joumal of Biological Chemistry, 245: 4975 - 4976 (1970) 
Table 1

\begin{tabular}{ll}
\hline HIV Reverse Transcriptase Complex & Bacterial Luciferase \\
Human a-Thrombin & Porcine Aldehyde Reductase \\
HIV-1 Protease & Human Transferrin \\
Fab against gp41 of HIV-1 & Factor D \\
Malic Enzyme & DD-Ligase from E. coli \\
Human Serum Albumin & DD-Ligase from S. tymp. \\
Recomb. Human Serum Albumin & B-Lactamase \\
Mouse Monoclonal Antibody & 2 domain CD4 (1-183) \\
Aridicin Aglycone & Recomb. Ricin-A chain \\
Horse Serum Albumin & Flavodoxin \\
Interleukin-4 & Lac Operator DNA \\
Interferon a-2b & Urease \\
Lac Repressor & Bovine Proline Isomerase Complex \\
Lysozyme & DNA Dodecamer: CGTTTTAAAACG \\
Canavalin & DNA Dodecamer: CGAAAATTCG \\
Human Proline Isomerase & Green Fluorescent Protein \\
Thermolysin & \\
\hline
\end{tabular}




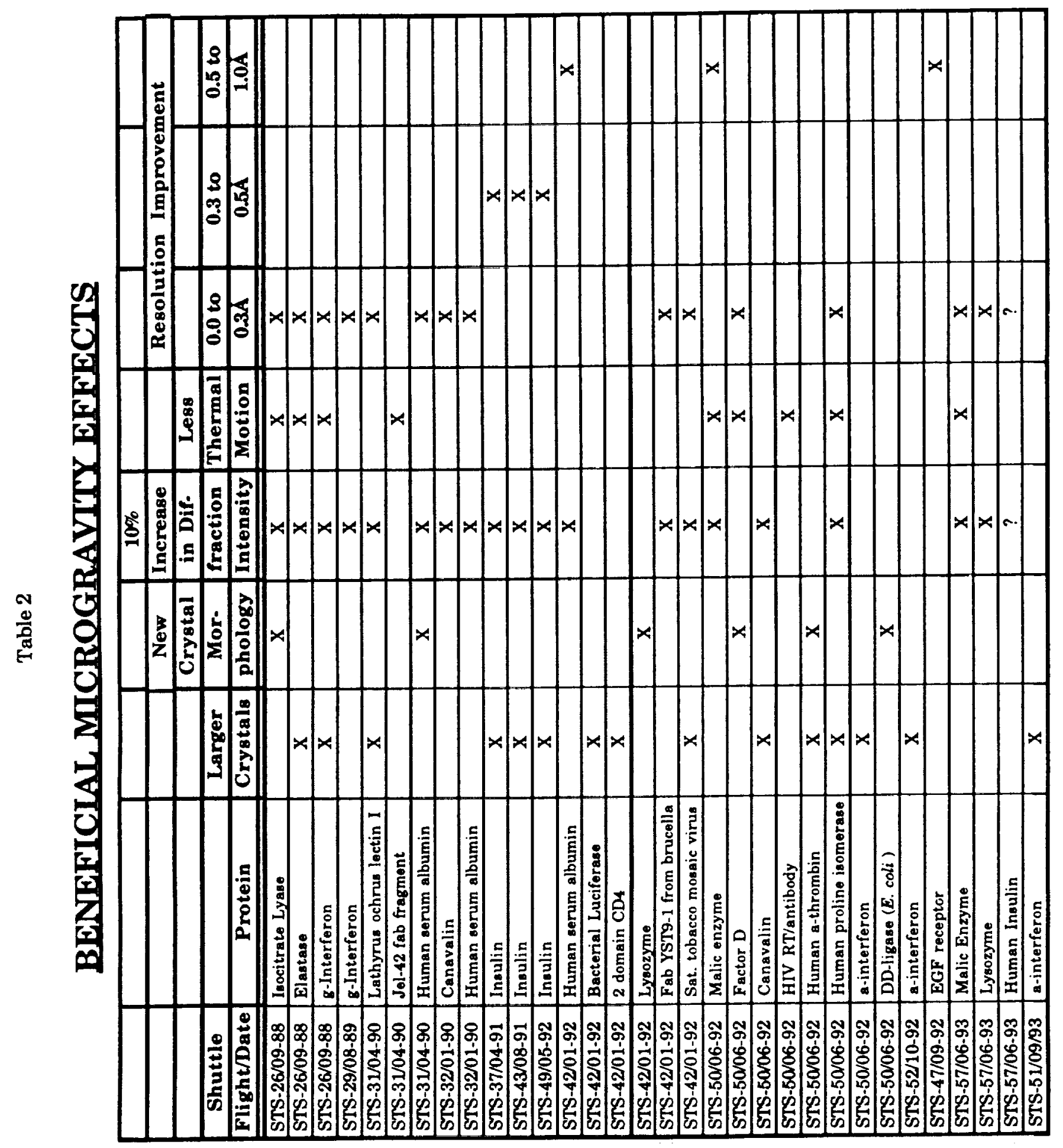




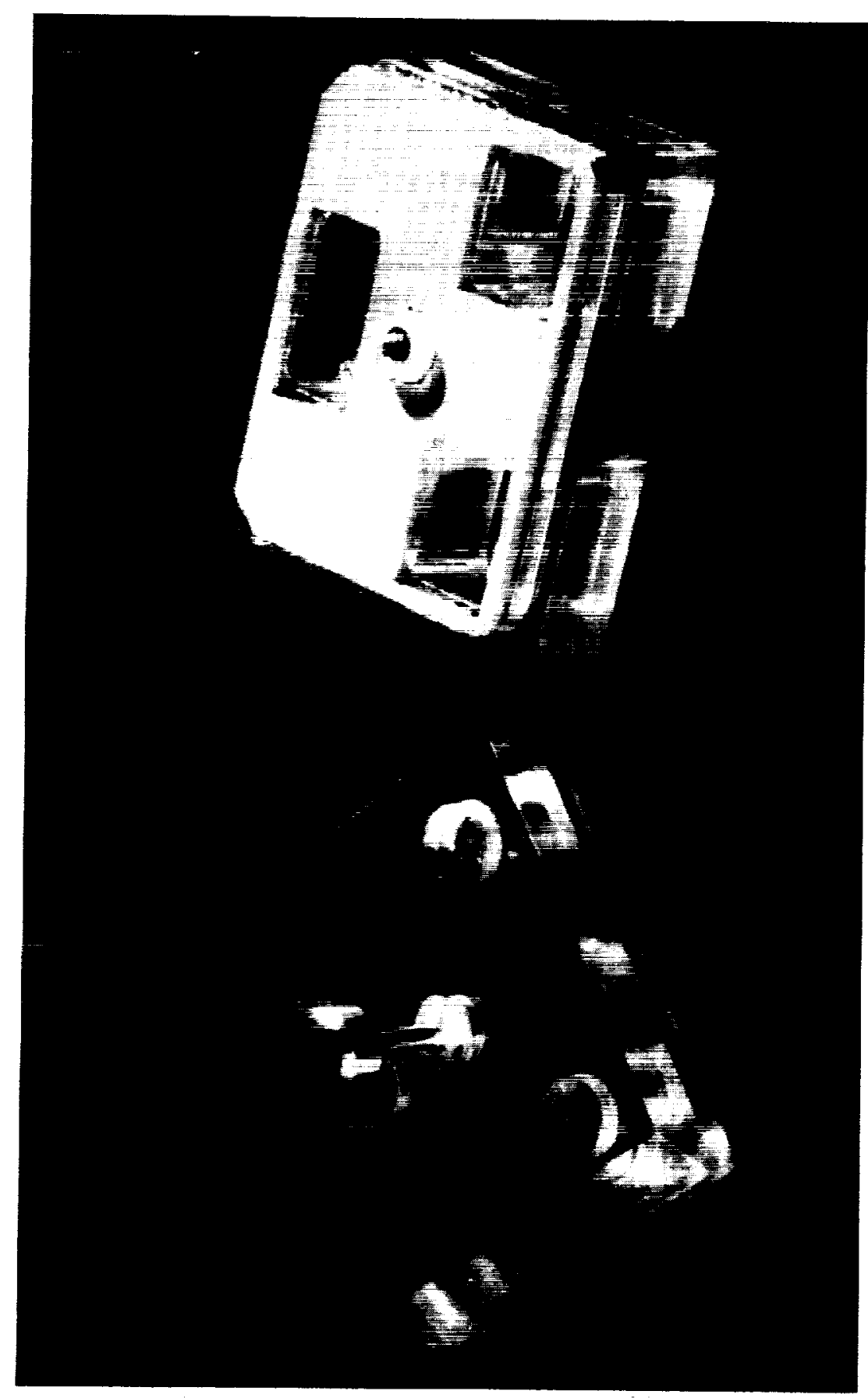

Figure 1 Vapor diffusion experiment chamber - The chamber consists of two polysulfone halves, one containing protein and one containing reservoir solution. The two sections are positioned with respective opposing chambers aligned for activation of the experiment. The experiments are deactivated by rotating the upper half $180^{\circ}$, thereby sealing all chambers on a neoprene gasket. 


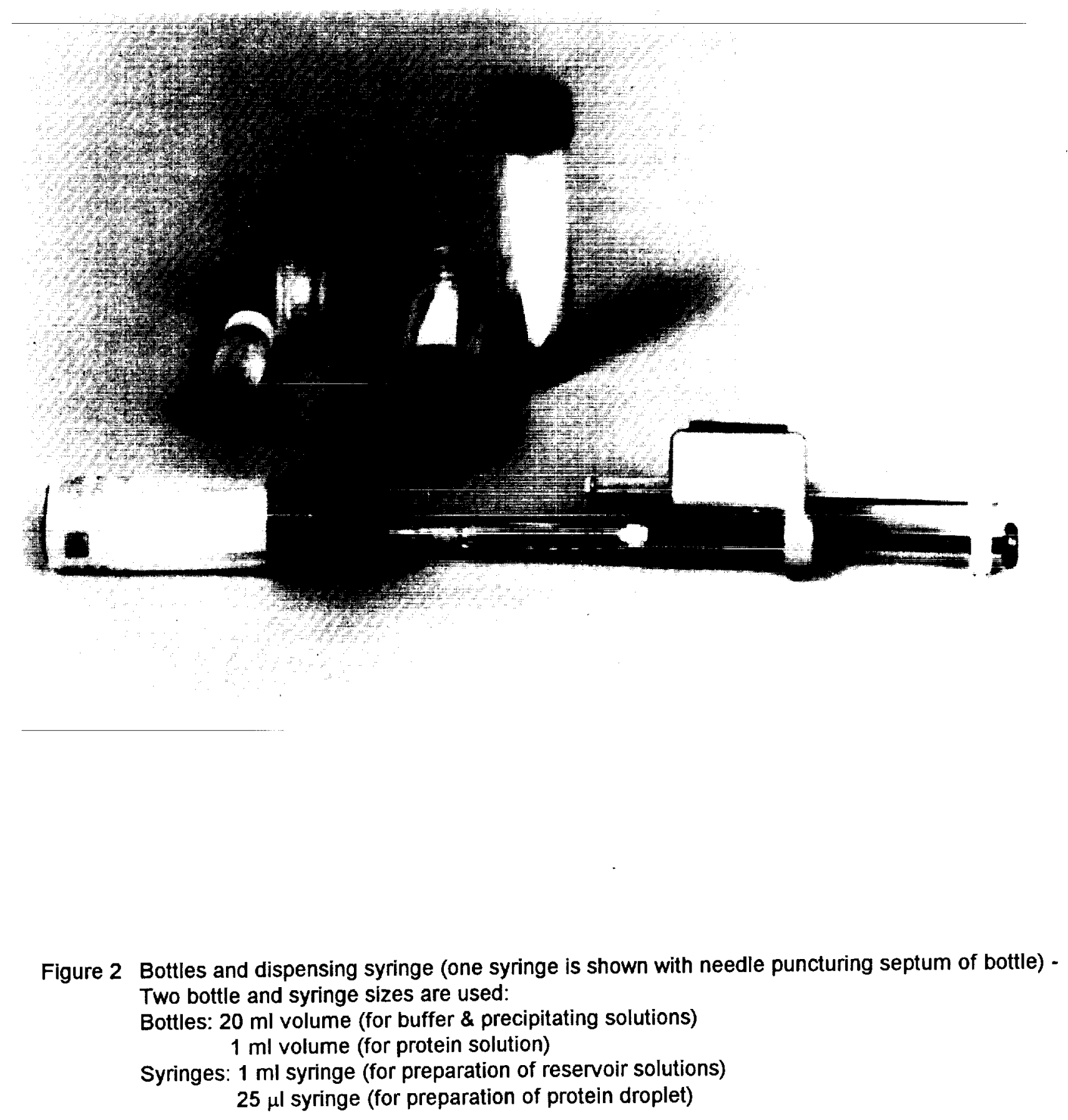




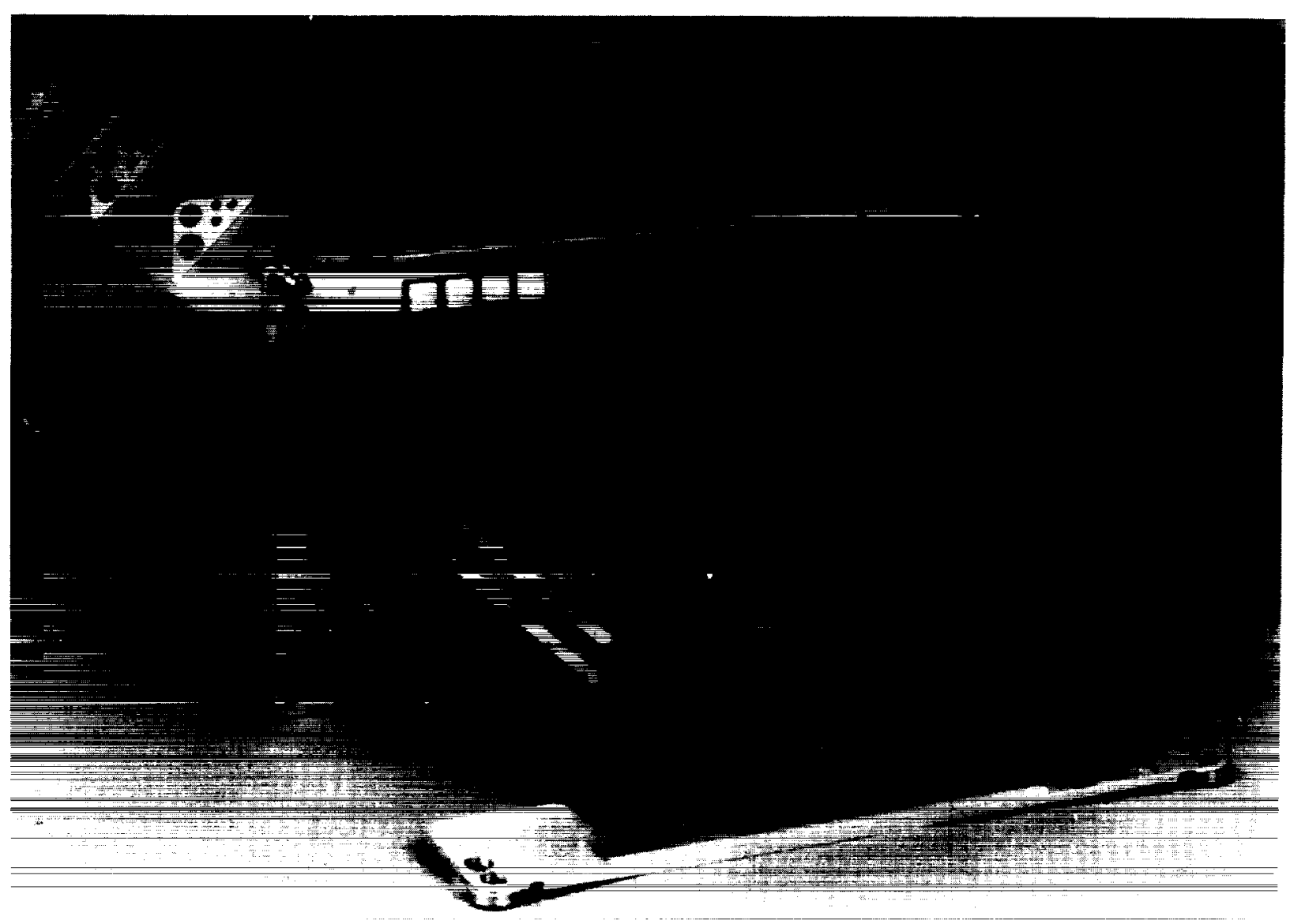

Figure 3 Refrigerator/Incubator module with containment tubes - The tubes are stored in a tray that slides out of the incubator to provide easy access. 

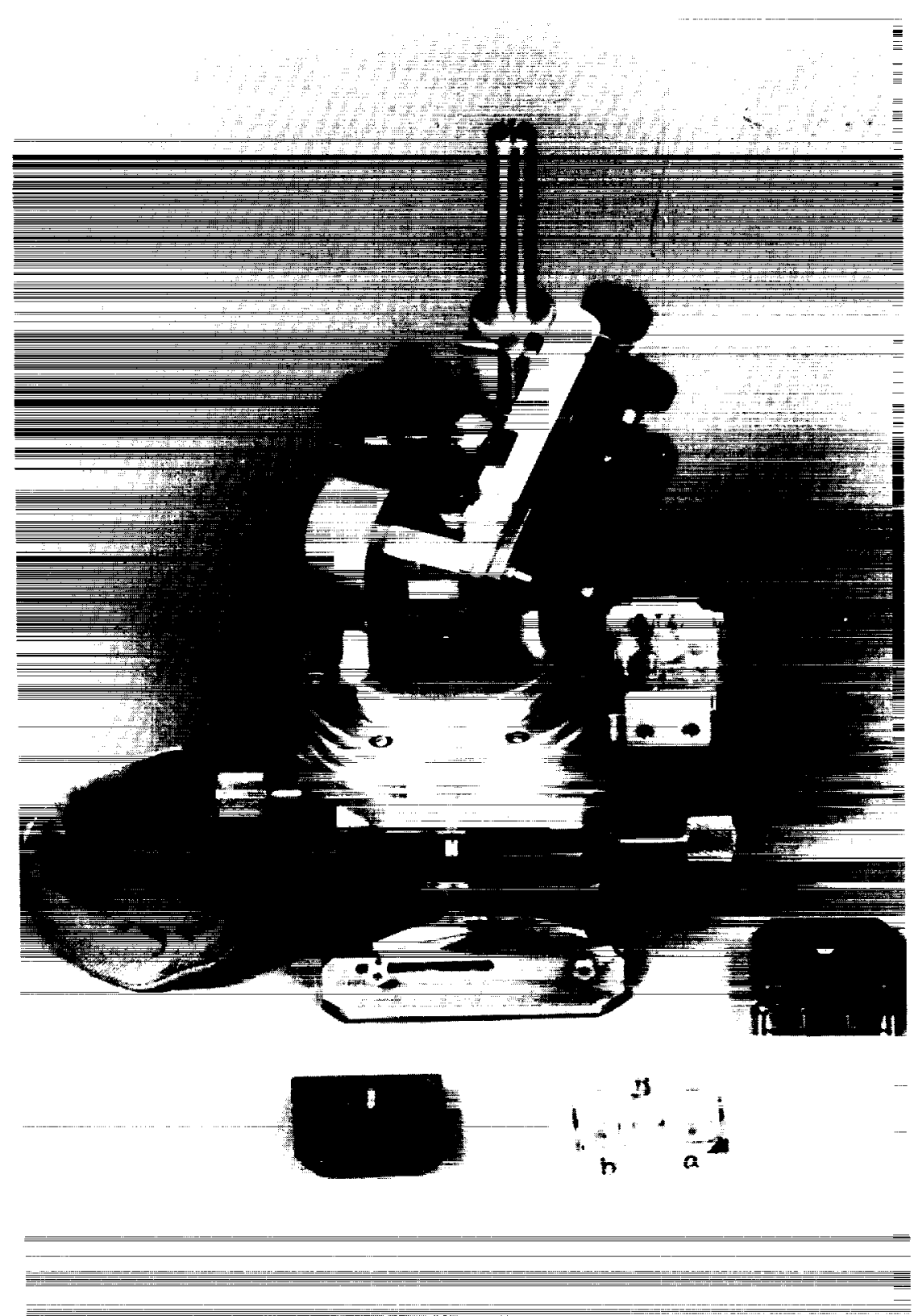

Figure $4 x-y-z$ translation stage with micromanipulator - A fiber optic bundle provides backlighting for experiment preparation and crystal observation. 


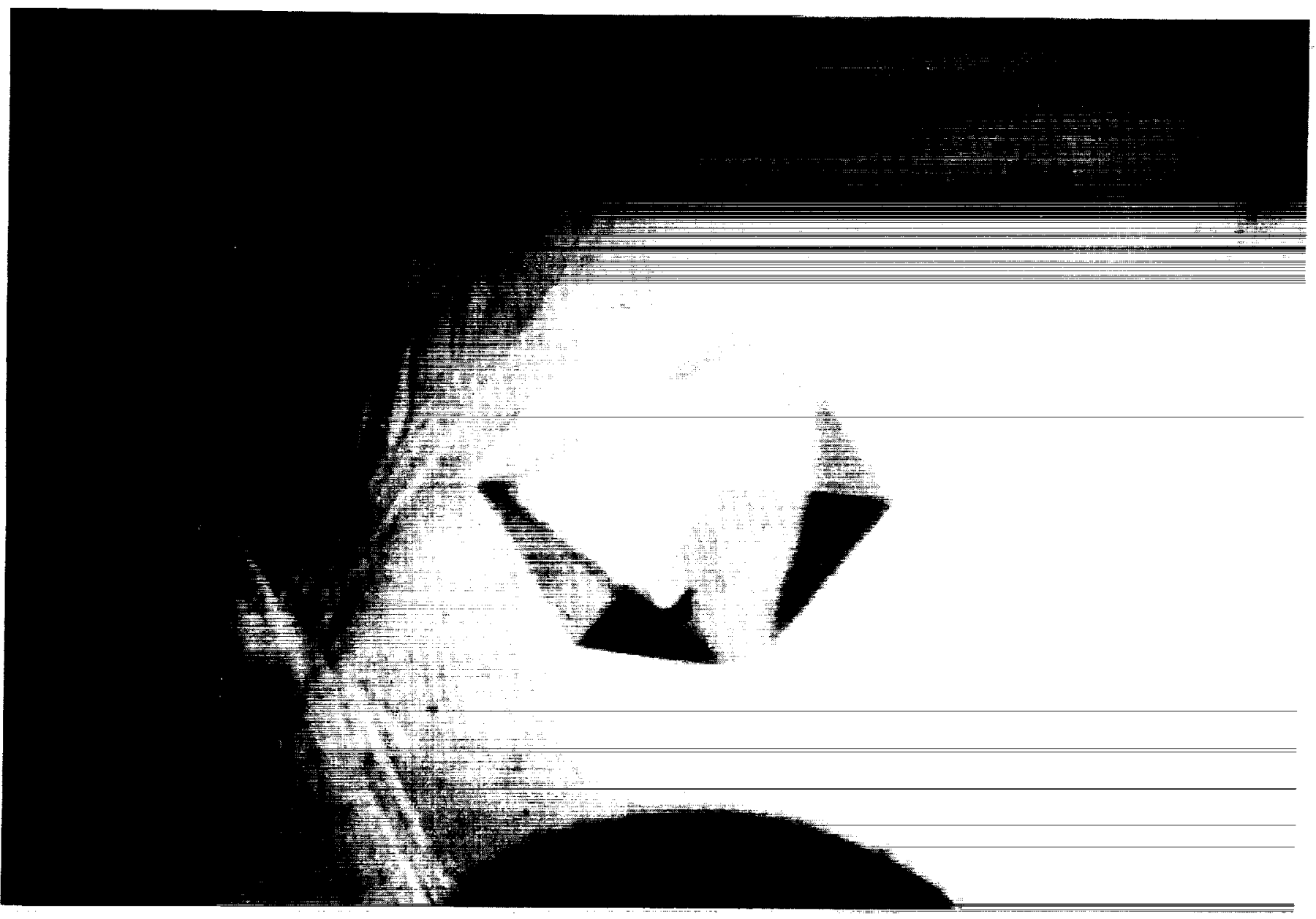

Figure 5 Crystal of malic enzyme grown in space. This space-grown crystal, although only $1 / 5$ the volume of the best earth-grown crystal, produced a significant enhancement in the quality and resolution limit of the diffraction data (see figures $6 a$ and $6 c$ ). 


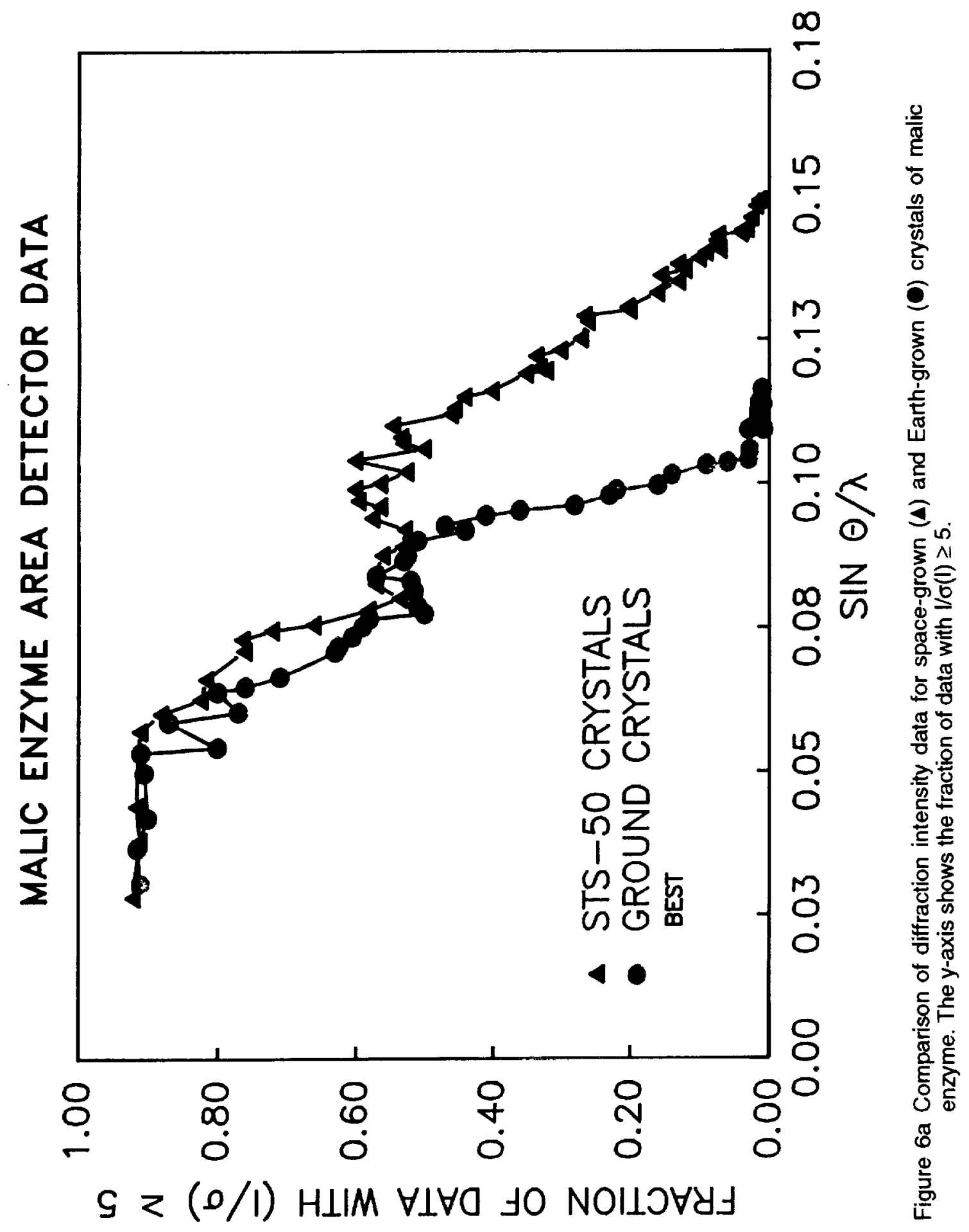




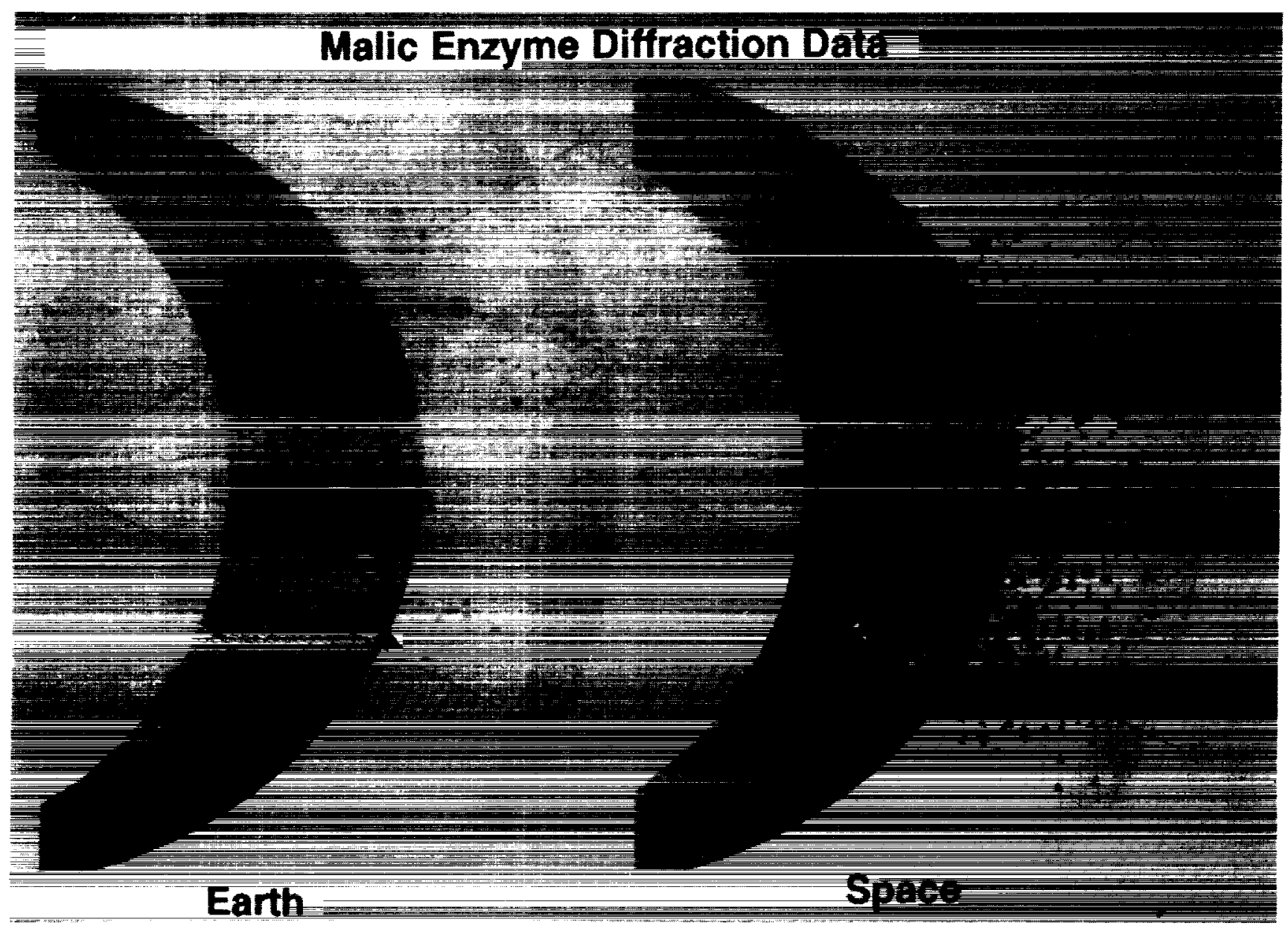

Figure $6 \mathrm{~b}$ Comparison of diffraction data for the best earth-grown versus best space-grown crystal (obtained on USML-1) of malic enzyme. The size of the earth-grown crystal was $0.04 \mathrm{~mm}^{3}$ and of the space-grown crystals $0.008 \mathrm{~mm}^{3}$. The space crystals yielded $25 \%$ more data, most of which occurred at the high resolution range. 


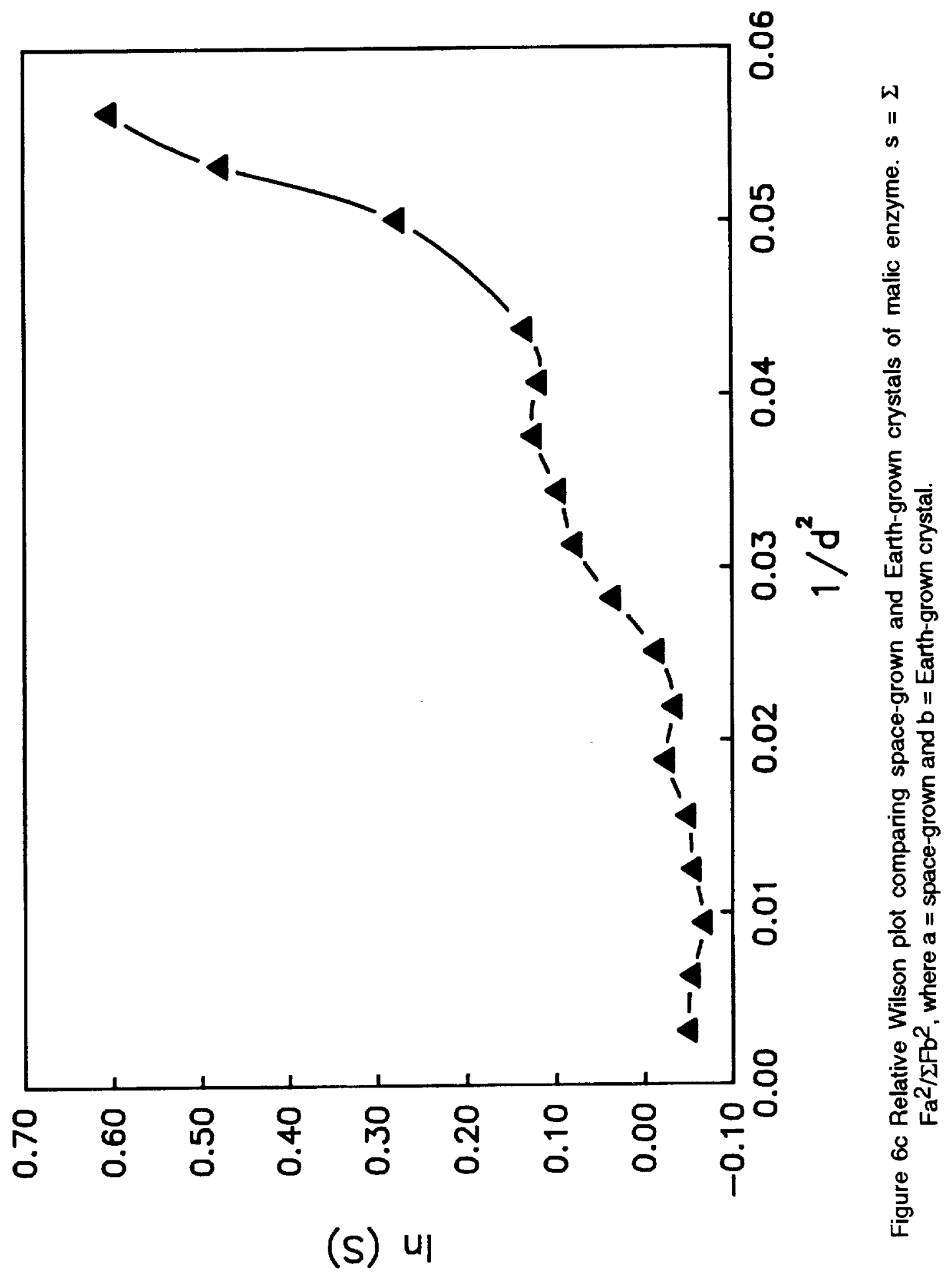




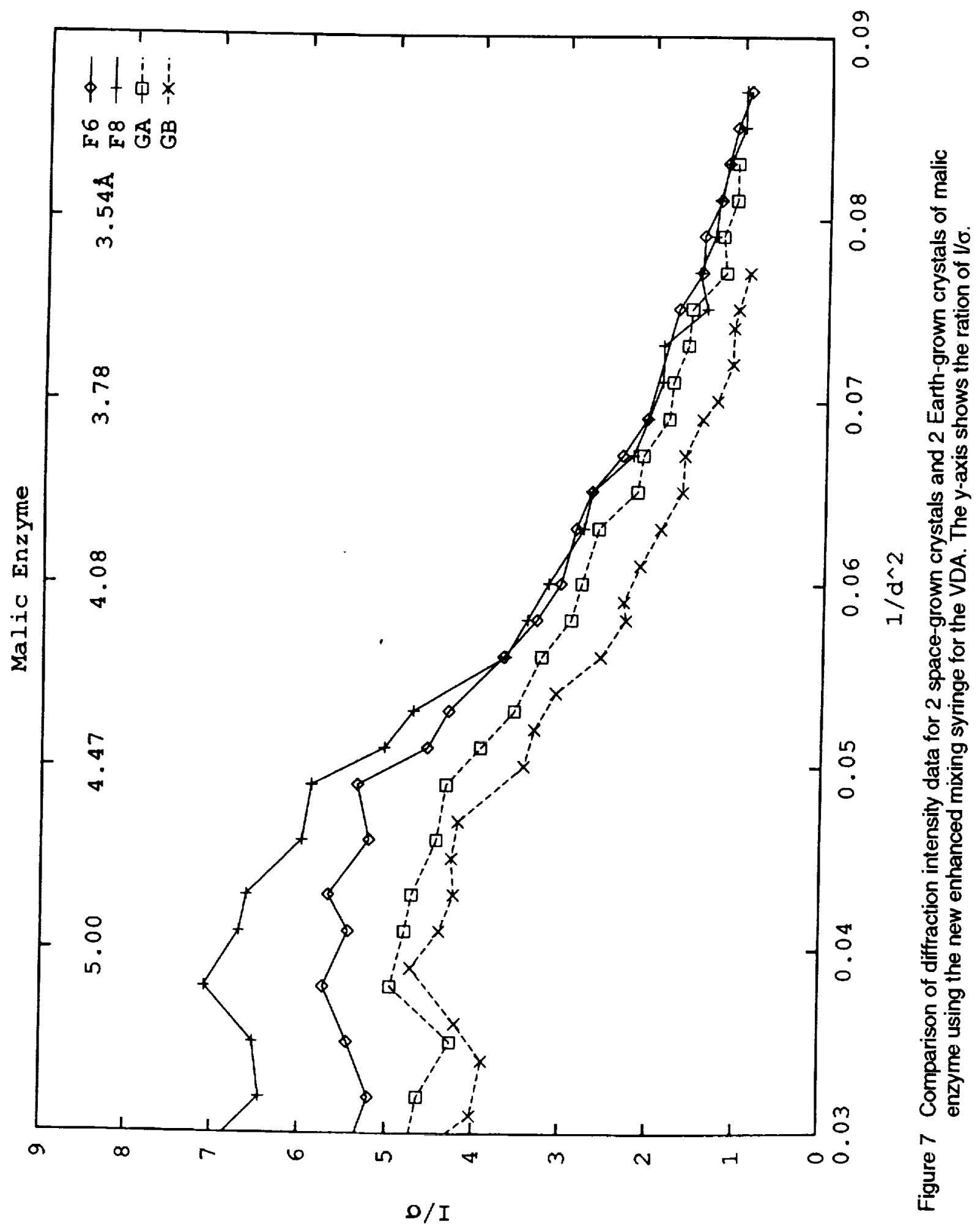




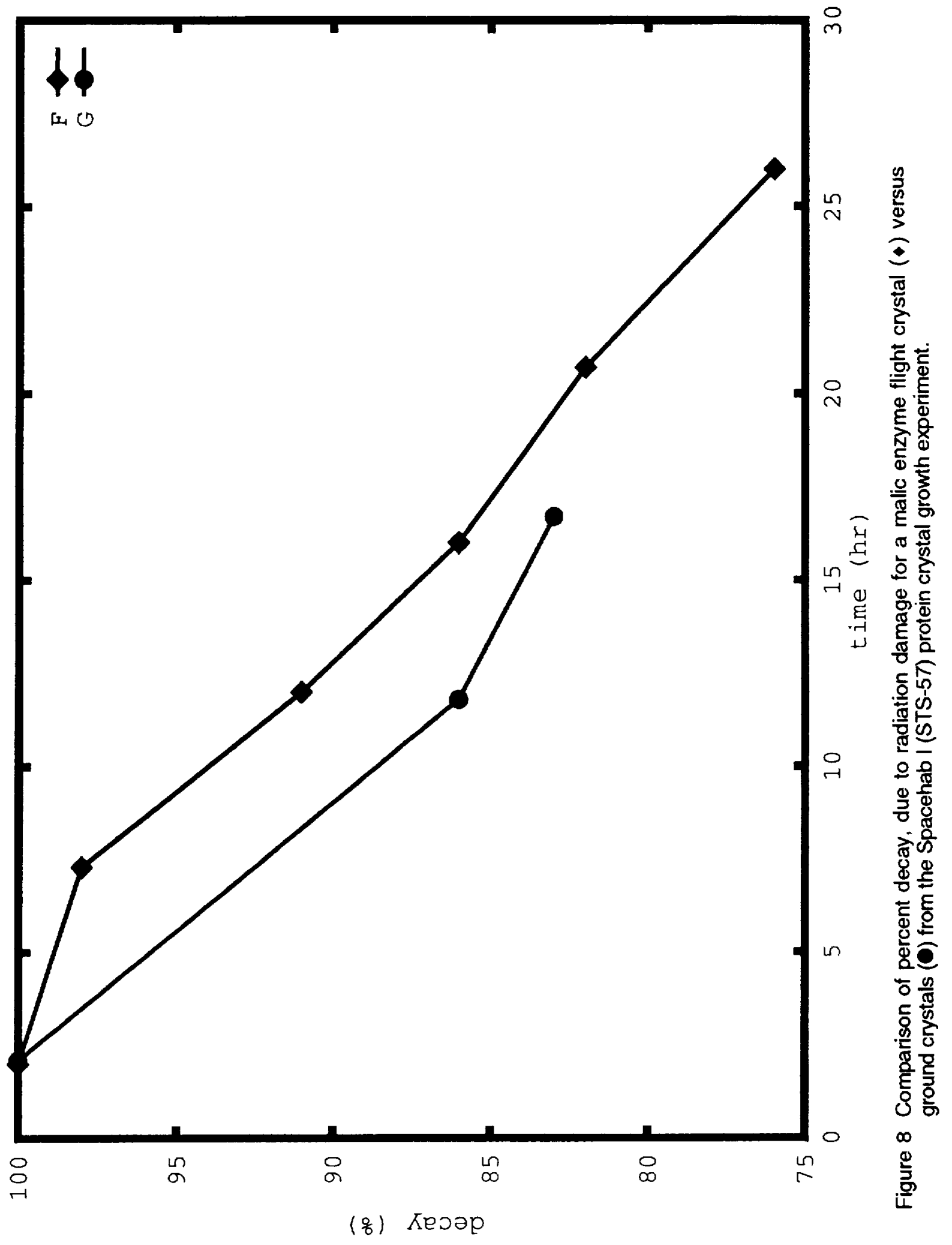




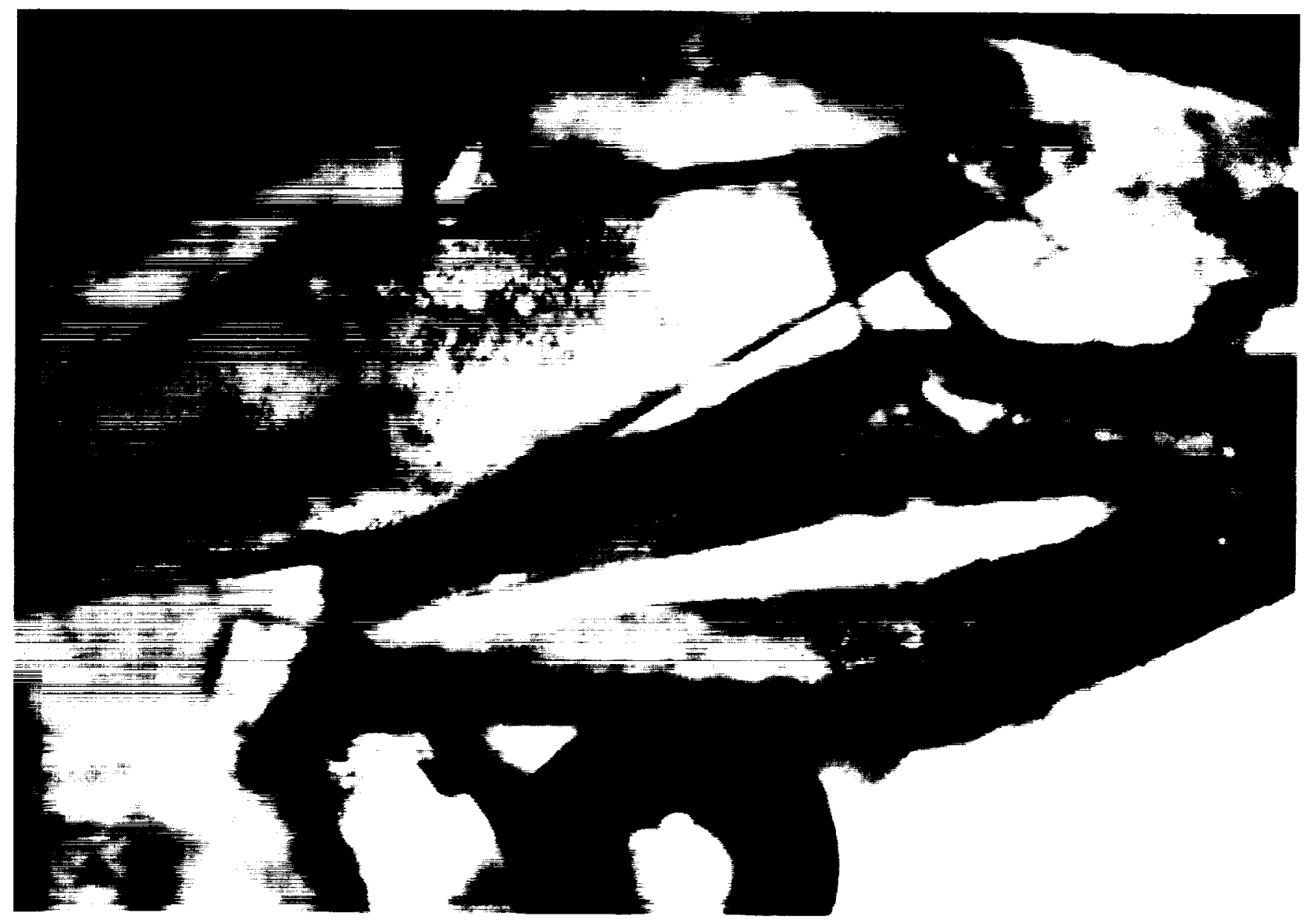

Figure 9 Space-grown crystals of bovine prolyl-isomerase from the USML-1 mission. 


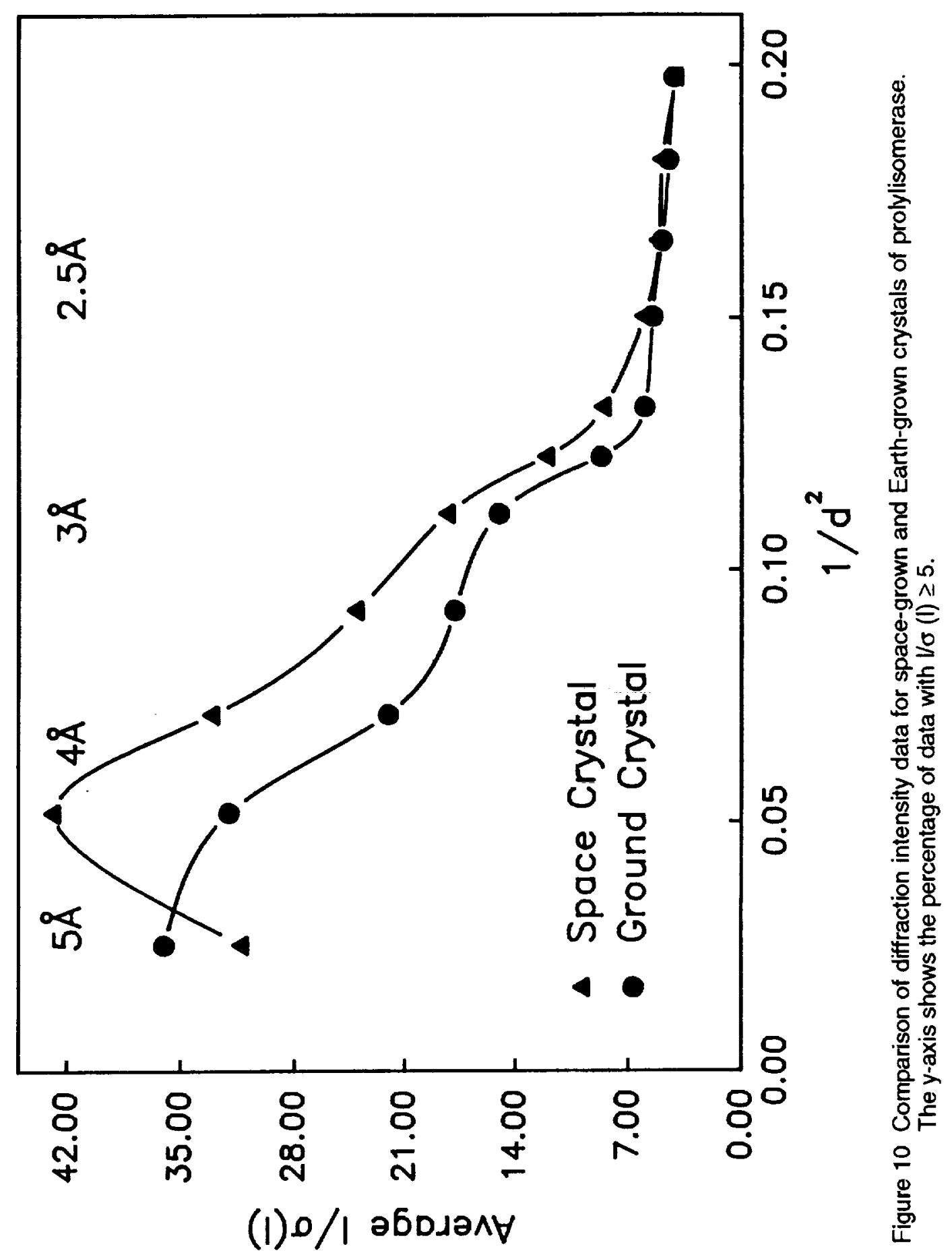




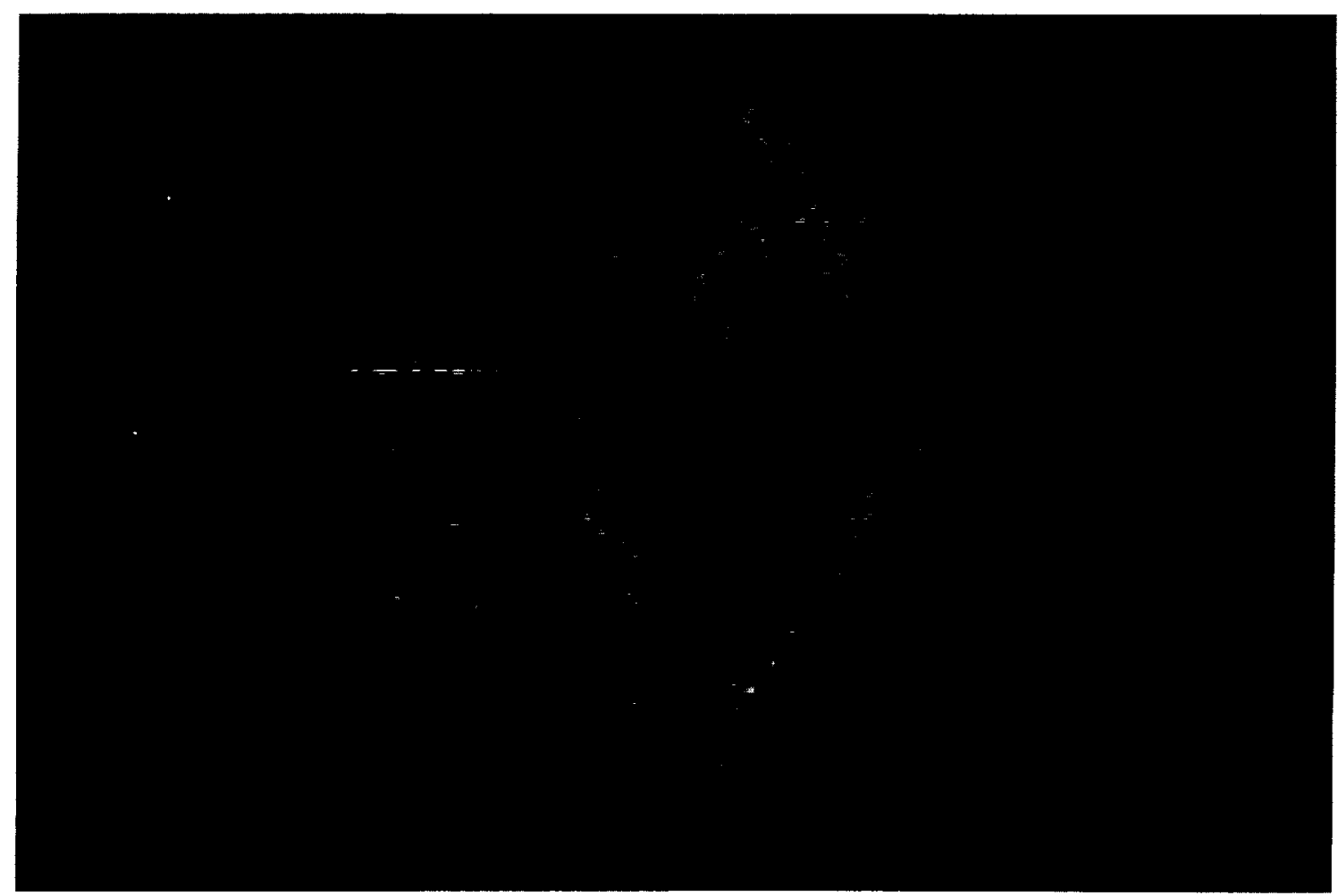

Figure 11 Three-dimensional structure of Factor $D$ determined using a combination of earth-grown and space-grown (from USML-1) crystals. 


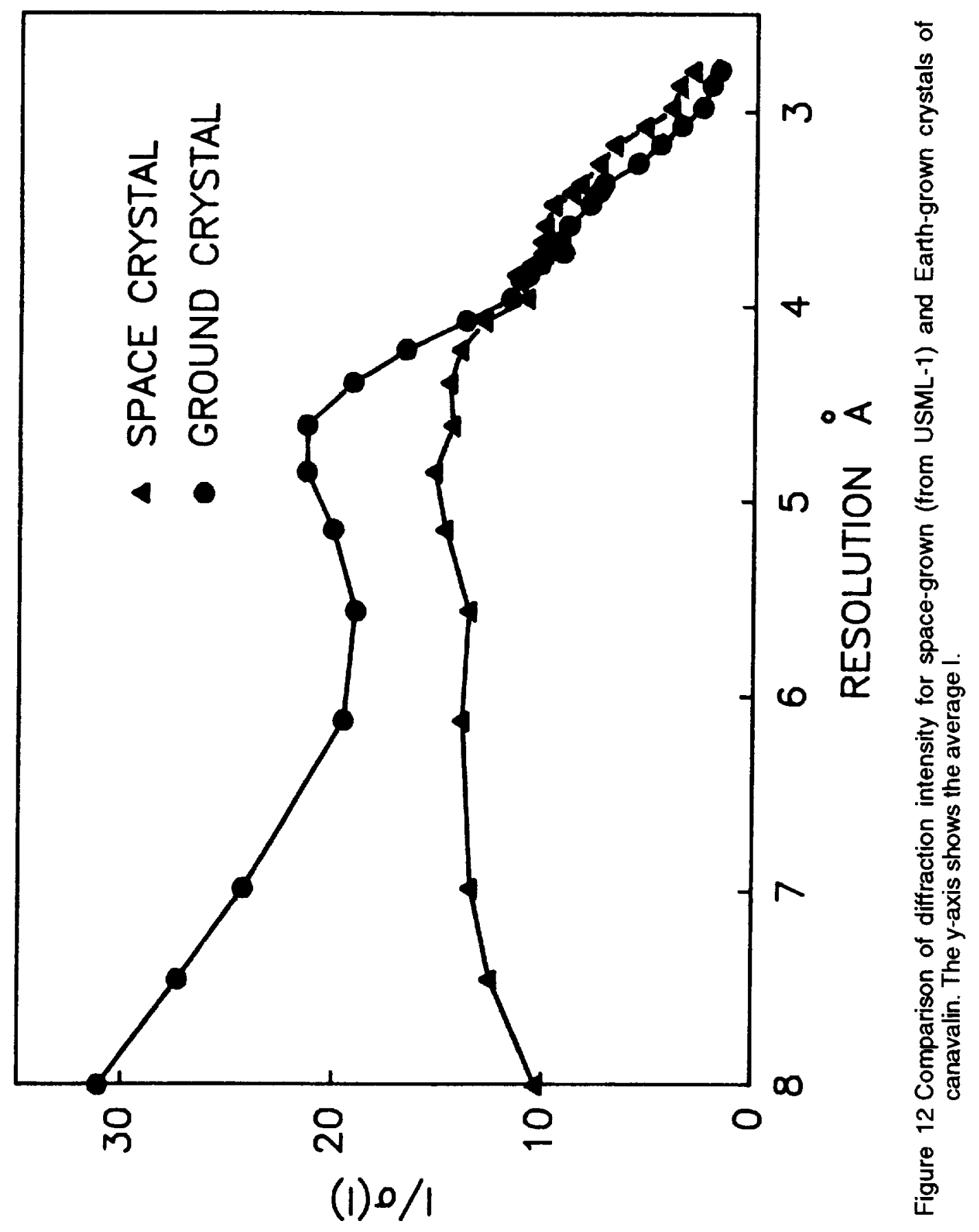




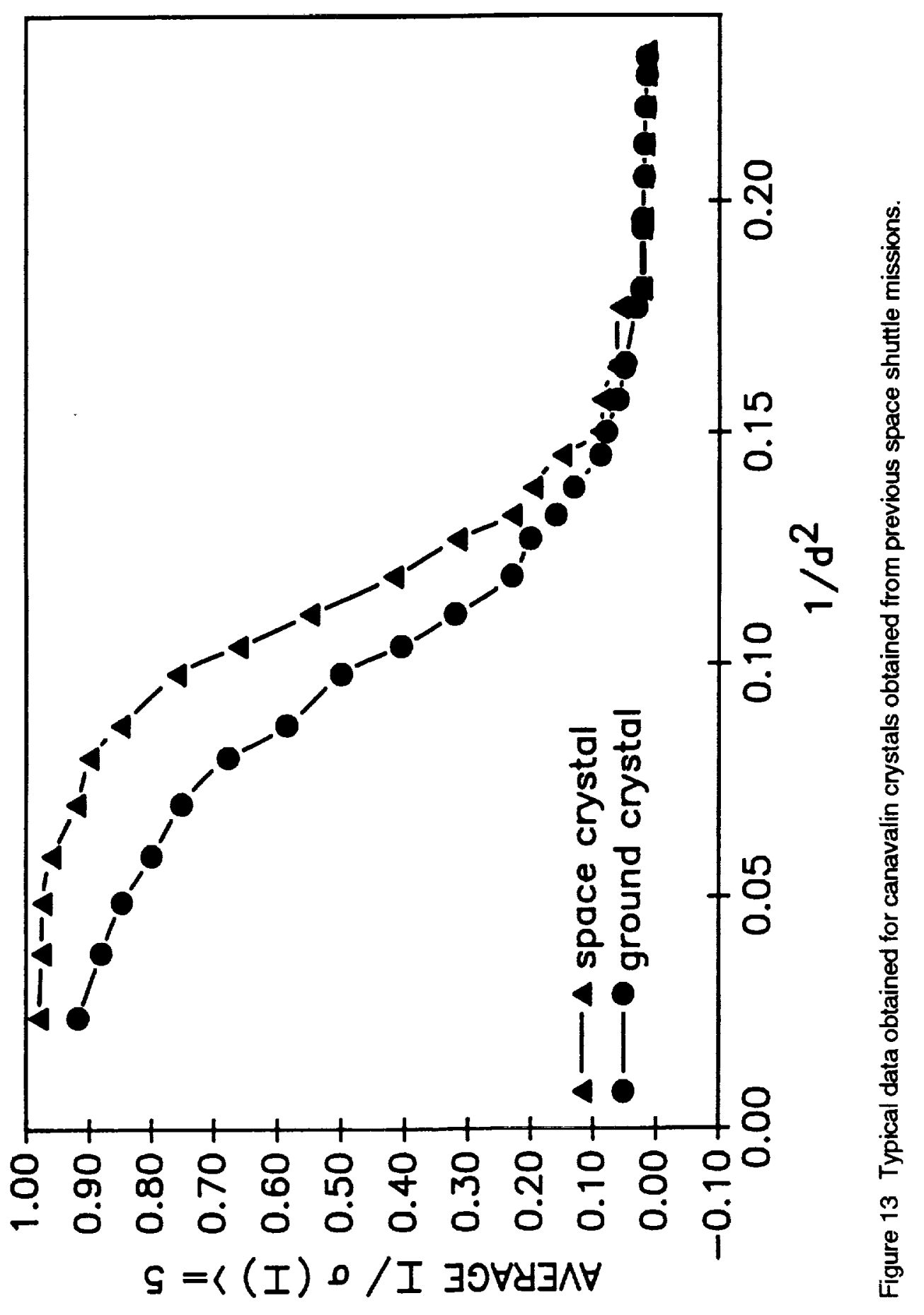




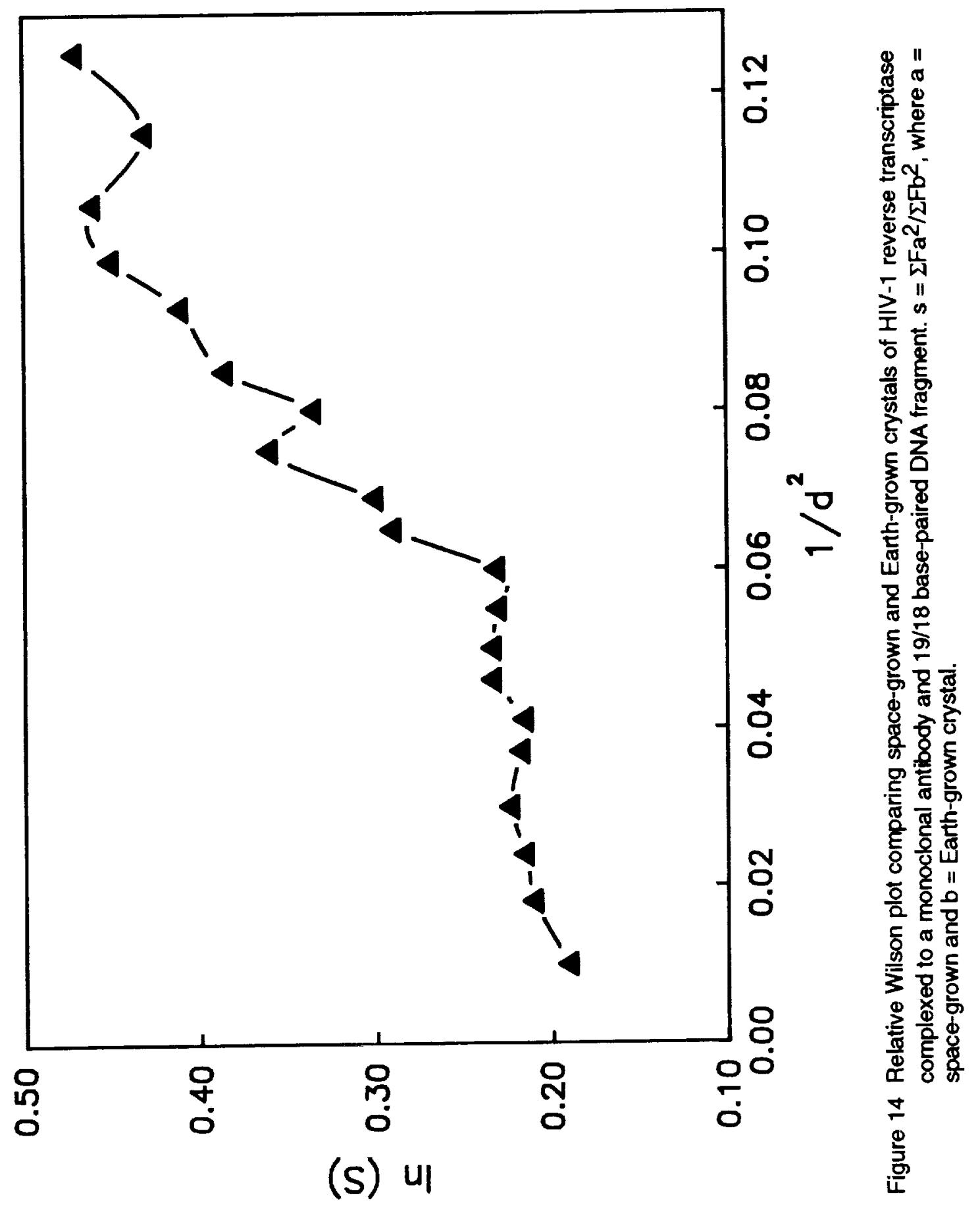




\section{Discussion}

Question: You mentioned about flow affecting crystal growth, what about the Brownian motion?

Answer: Well it is certainly more gentle than the convective flow due to buoyancy, and we measured those for a protein crystal. For example with lysozyme, the flow is moving up, I believe, at 1 micron per second. It was something like that. It was a lot faster than you are ever going to get just from Brownian

motion. I don't know what amount of motion will harm a crystal and what won't. Those crystals that floated through the bottle benefited from that motion. They grew much larger than the ones that were attached. Possibly a controlled flow is what we need to look at in microgravity and also to optimize the length of a shuttle mission to get a crystal that is large enough that we can use.

Question: Were you concerned at all about activities occurring on the shuttle during the growth, jitter effects and things like that? Did you ever get a chance or are you planning to look at that in a particular way?

Answer: I don't know what vibrations will do to protein crystals as they grow. Unlike the semi-conductor crystals these are in all different orientations because they are free in solutions. But we have no data on what levels of vibrations may harm protein crystals, so I am not planning to look at that. We have enough things we are worried about, in terms of trying to understand the kinetics of the growth, etc. I think that is the first thing we need to hit. But I know and most protein crystallographers know that vibrations hurt protein crystals. We have a cold room where we grow crystals and the compressor is in another part of the building because if we attached it to the cold room, that vibration gives you a shower of little crystals. So vibration hurts but I don't know at what levels and where you draw the line.

\section{Question: Is it isolated at all or do you get all the vibrations?}

Answer: The buildings are not but we have incubators that are on isolation tables in my lab. All of the incubators are isolated.

Comment: Computational fluid dynamic modeling has shown that vibrations in the $1-10 \mathrm{~Hz}$ range are the most detrimental for PCG as far as flow is concerned. It tends to wiggle the flow right next to the crystal and it does not take long for the flow to sweep past the crystal because the crystal is so small. This tends to disrupt any profiles, diffusion or otherwise next to the crystal. What it means for attachment kinetics is a whole new ball game and needs to be further researched. But we think that it is a good isolation candidate since frequencies in the $1-10 \mathrm{~Hz}$ range can be isolated by not only active but also by passive means. 
Answer: On STS-57 we took two of the Malic enzyme crystals grown in this syringe and did something very interesting. What we did in the analysis is to take reflections down along all three principle axes and monitor those over and over as you expose those crystals to the $x$-ray radiation. We did that with two from space and two from ground and you are looking at the percent decay. The blue curve is the ground data and the top one, the space data from these two smaller space crystals. They (space crystals) last longer in the $\mathrm{x}$-ray beam, and that is a dramatic improvement. This is the first time we have really done this kind of analysis. A lot of data was collected over three days to do this. Other investigators have said this needs to be done, but have never done this kind of experiment. They just collected the data but they didn't keep collecting the swath of data over and over. We did that on this mission. Of course if it does not decay as fast, that should mean it is better ordered once again.

Question: Is it true in general, that space crystals are smaller than Earth grown crystals?

Answer: I think it is definitely due to the fact that it takes too long for these protein molecules to diffuse to the crystal. There are some cases where they are much larger even in the VDA. Unlike small molecule crystal growth, when a protein growth nucleates the supersaturation level is anywhere from two times the normal concentration in solubility to up to $150,200,300$ times supersaturation. Depending on the supersaturation level, it is conceivable that you can get a pretty big crystal in space. I think that is why it has happened in some cases. Generally, the crystals that come back from space are much smaller than Earth crystals and most of this data that I showed you is from space crystals that are much smaller. In fact if you look at that table, about $70 \%$ of those space crystals that were superior resolution were much smaller than the Earth crystals.

It is a double edged sword, because the longer you stay in orbit, the protein degrades and those crystals that have grown will begin to degrade. What you need is to grow a crystal and when it reaches an optimum size, smaller than a capillary, collect data on it in space and we plan to do that on space station.

Question: Was the crystal data for the transcriptase space grown crystal better than ground data? Answer: They were very comparable. The only thing that was better was that the Wilson plot indicated less thermal motion which does indicate its better order. But the data in the diffraction plot is so close that I am not going to go out on a limb and say that the space data was better.

Question: In light of your last comment, is the data still useful?

Answer: Oh yes. You can use it to help complete the structure. It is as good as any data set that they have put on the ground. Certainly. Probably a tiny bit better. 


\section{Discussion from the Glovebox Session}

Question: You said in space whenever you were using your syringe, if you went too fast it would develop bubbles. Did that ever happen when you were doing tests on the KC-135?

Answer: We did but I never saw anything like I saw up in flight. The amount of bubbles I saw up there depended on the solution we were using. The first day, I think Carl Meade did human serum albumin and he had some problems with bubbles and the next day I had to do the same one but his was clone material and mine was real material. I am not sure which way it was but we used the same precipitate agent. I had bubbles, so I repeated his and got lots of bubbles but I found with other solutions it was not near as bad. There was a marked difference, depending on the solution, on how bad it was. And I never noticed from the $\mathrm{KC}$, that bubbles were going to be as bad a problem as they were. Yes. We did get some on the $\mathrm{KC}-135$ flights.

Question: You mentioned that the ability to do certain mental processes that would be normal (on Earth) you found perhaps a little more difficult. We were always wondering and maybe you can comment on this. You are running an operation that is very tightly timelined, literally almost by the minute, and you are running behind as you said early on. How do you sort of mix that requirement with the fact that you have to think about what you are doing, and that, to me, sounds like something they have looked into, but you have experienced it?

Answer: I felt a world of pressure on me. These proteins are really expensive. Some of the companies gave me protein for this flight that was worth over $\$ 100,000$. To make mistakes that are obvious on the ground when you can later look at it is different. I felt a lot of pressure. I was real nervous because I was way behind and I did not do the Glovebox experiment as carefully as I should have. I think I was extruding, sometimes a drop, and I would think, was that a bubble that just came out? On the ground I would have just sucked it back up; but I said, "I just got to keep going". So my accuracy was not what it should have been. So, what I tried to do was to pick the ones that were most valuable. We had a priority list and I tried to give them my attention; but, to be honest with you, the last 12 proteins on that priority list, I didn't set up a lot with them. I did them a lot faster knowing that they were not as valuable, and I knew that they didn't have as much chance for success. In fact, some had very little chance especially at the end. My haste, and not doing a careful experiment, I think, showed in some cases but it is hard to tell where. But I know sometimes when I dispensed liquids it could not be exactly right, but I could not go back and do it again.

Question: Did you put this down in your lessons learned list? 
Answer: Oh, I have. For USML-2. For USML-2, I am proposing 5 proteins, 30 hours for that. So the poor crewmen can relax and do it right.

Question: Did you have any of the same proteins in the glovebox as in the middeck experiment? Answer: Yes, I had about 4 or 6 that were duplicated across there. Reverse transcriptase was one and they were about equal in quality, Glovebox and the other one. It is hard for me to tell you because they merged them. The PI merged all those because he had to collect 22 crystals on a synchrotron. So all that data got put together. Malic enzyme had flown on two other missions in the VDA's with no crystals. It is mainly because of the viscous solution used. So it just flew in the Glovebox. There were a few others like that where they had viscous solutions and we got crystals in the Glovebox, not always big ones, and didn't get it in the VDA. Just like in every other mission, when we have polyethylene glycol, we typically got, and USML was no exception, just a clear solution or a massive precipitate. If you got something that does not mix and the precipitate is sitting here in the protein, right at that interface you have a high concentration and it will usually tend to make it just precipitate out. That happened on USML in the VDA.

Question: I was just going to mention that the other day you said you only got three hours of sleep at night on the fight. That may have as much to do with the much lower mental capacity as anything else? Answer: I think with me it was a lot of things. I didn't take sleeping pills. It wasn't three hours every night. Some nights I would get up and then go back to sleep a little later but I didn't get a lot of sleep. But my shoulder hurt the last 5 days. Ellen was wrapping my shoulder and that kept me up. It was just a lot of things but I didn't get a lot of sleep and maybe that affected my mental capacity. I think I would have done that crystal mounting procedure if I wasn't in pain. I would have gone and done it because I know it was important to test that. At that point, I said I had done enough and I am just going to put those things away.

\section{Question: You were mentioning that you felt almost immediately a reduction of mental capacity?}

Answer: Well the first two days I guess everybody really feels it but then it gets a lot better and you feel sharp but looking back now I just don't think I was ever what I would be down here. Carl, you probably don't agree with me. We had talked about this a little bit. What do other payload specialists say?

Carl Meade: No. I don't know, but I am surprised, and everybody else is surprised, actually. I think this is an explainable phenomenon. Quite honestly I do not understand why this is a new find.

DeLucas: Well, it is not a new find, but I think people here don't realize it. I did not realize that it could have this kind of effect. It is the increased inner cranial pressure. I think anybody in the medical community will tell you, especially within the first two days. 
Carl Meade: Within the first two days, yes. But once everybody gets to their equilibrium position I think the decreased mental capacity is certainly a function of the environment. I think that most people get up to $100 \%$. At least I speak for myself. I think that I am up to $100 \%$. Where that absolutely may be, who knows? But, you say you are not, but, thinking back on it, I think that is sort of a predictable position. You are in a different environment. If you gave me a bunch of training manuals and then stuck me in your lab for two weeks and said, "quick, go produce something, and, by the way, we are watching the clock !", I would be fumbling around and falling down.

Question: I was just wondering, did you get any diffraction data from Canavalin or did all the crystals disintegrate?

Answer: Oh, yes we did. From the VDA, it was very good. From the Glovebox, however, the big one had degraded very significantly. I showed the curve; it actually went above the ground stuff at high resolution; but, at low resolution the signal/noise ratio was much worse than the ground crystals which were smaller and so that just got hurt tremendously.

Question: So that data was not any better than ground data?

Answer: No. I would say that is worse.

Question: You have a tremendous amount of surfactants in your solutions and because of that, when you did have a cavity form, there was a chemical component stabilizing it and, so, I assume if you tried to put a little more pressure on that cavity and tried to collapse it, it did not work. Is that the case? I mean you form a vapor cavity if your external pressure is above the vapor pressure then you collapse the bubble?

Answer: Are you talking about the bubbles in the syringe? I had a lot of little bubbles and I could get them all to the end of the needle and just push the air out. That was no problem.

Comment: Since chemical diffusion is very slow and the bubble is chemically stabilized, you are stuck with physically removing the bubble as opposed to collapsing it.

Answer: Well, I never tried to collapse it. I tried to get it out of the end of the syringe. The only thing that I said that if it is at the other end, just like it would on Earth, you are going to compress that air and again you won't dispense accurate amounts.

Question: Could you comment on the effect of dissolved gases in your solutions? 
Answer: It is true that in many cases the liquids have dissolved gases in them and most investigators worked hard to prepare their liquids by taking the dissolved gas out. That means putting them under vacuum and heating them, and so forth, and then placing them into containers without any air. STDCE put their fluid in bags. We have flown on several flights all the proteins. We degassed everything. Not only did we degas, it but we vibrated it while we degassed it to get as much air out as we could and it has never made any difference in the bubbles generated by the syringes, i.e., the big syringes that we have in the VDA. I think as the liquid moves, it grabs the surface and cavitates and the faster you move it across there you are just trapping air. Degassing is important to do, but we never saw a difference. Some of our investigators degas now, and some don't, just because we haven't been able to tell a difference. 1 think, it is so bad because of the syringes' mechanism itself. 
